\title{
Exploring the Coordination of Plutonium and Mixed Plutonyl-Uranyl Complexes of Imidodiphosphinates
}

DOI:

10.1021/acs.inorgchem.9b00346

Link to publication record in Manchester Research Explorer

\section{Citation for published version (APA):}

George, K., Muller, J., Berthon, L., Berthon, C., Guillaumont, D., Vitorica-Yrezabal, I., Stafford, H., Natrajan, L., \& Tamain, C. (2019). Exploring the Coordination of Plutonium and Mixed Plutonyl-Uranyl Complexes of Imidodiphosphinates. https://doi.org/10.1021/acs.inorgchem.9b00346

\section{Citing this paper}

Please note that where the full-text provided on Manchester Research Explorer is the Author Accepted Manuscript or Proof version this may differ from the final Published version. If citing, it is advised that you check and use the publisher's definitive version.

\section{General rights}

Copyright and moral rights for the publications made accessible in the Research Explorer are retained by the authors and/or other copyright owners and it is a condition of accessing publications that users recognise and abide by the legal requirements associated with these rights.

\section{Takedown policy}

If you believe that this document breaches copyright please refer to the University of Manchester's Takedown Procedures [http://man.ac.uk/04Y6Bo] or contact uml.scholarlycommunications@manchester.ac.uk providing relevant details, so we can investigate your claim.

\section{OPEN ACCESS}


This document is confidential and is proprietary to the American Chemical Society and its authors. Do not copy or disclose without written permission. If you have received this item in error, notify the sender and delete all copies.

\section{Exploring the coordination of plutonium and mixed plutonyl- uranyl complexes of imidodiphosphinates.}

\begin{tabular}{|r|l|}
\hline Journal: & Inorganic Chemistry \\
\hline Manuscript ID & ic-2019-003464.R1 \\
\hline Manuscript Type: & Article \\
\hline Author: & 29-Mar-2019 \\
\hline Authete List of Authors: & $\begin{array}{l}\text { George, Kathryn; University of Manchester, CEAS } \\
\text { Muller, Julie; CEA Marcoule } \\
\text { Berthon, Laurence; CEA, Chemistry } \\
\text { BERTHON, Claude; CEA, DRCP, SCPS } \\
\text { Guillaumont, Dominique; CEA, DRCP } \\
\text { Vitorica-Yrezabal, Inigo; University of Manchester, School of Chemistry } \\
\text { Stafford, Helen; University of Manchester } \\
\text { Natrajan, Louise; University of Manchester, Chemistry } \\
\text { Tamain, Christelle; CEA, DEN/DRCP }\end{array}$ \\
\hline
\end{tabular}

\section{SCHOLARONE ${ }^{m}$ Manuscripts}




\title{
Exploring the coordination of plutonium (IV and VI) and mixed plutonyl-uranyl complexes of
}

\section{imidodiphosphinates}

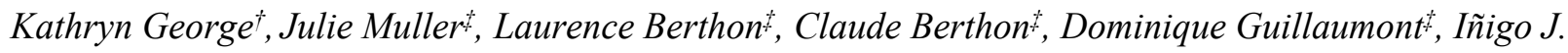
Vitorica-Yrezabal ${ }^{*}$, H. Victoria Stafford ${ }^{\dagger}$, Louise S. Natrajan ${ }^{*}{ }^{*}$ and Christelle Tamain ${ }^{* *}$

$\dagger$ The Centre for Radiochemistry Research, School of Chemistry, The University of Manchester, Oxford Road, Manchester, M13 9PL, UK.

\$Nuclear Energy Division, RadioChemistry \& Processes Department, CEA, F-30207 Bagnols-sur-Cèze, France

\begin{abstract}
The coordination chemistry of plutonium(IV) and plutonium(VI) with the complexing agents tetraphenyl and tetra-isopropyl imidodiphosphinate (TPIP- and TIPIP-) is reported. Treatment of sodium tetraphenylimidodiphosphinate (NaTPIP) and its related counterpart with peripheral iso propyl groups (NaTIPIP) with $\left[\mathrm{NBu}_{4}\right]_{2}\left[\mathrm{Pu}^{\mathrm{IV}}\left(\mathrm{NO}_{3}\right)_{6}\right]$ yields the respective $\mathrm{Pu}$ complexes $\left[\mathrm{Pu}(\mathrm{TPIP})_{3}\left(\mathrm{NO}_{3}\right)\right]$ and $\left[\mathrm{Pu}(\mathrm{TIPIP})_{2}\left(\mathrm{NO}_{3}\right)_{2}\right]$. Similarly, the reactions of NaTPIP and NaTIPIP with a Pu(VI) nitrate solution lead to the formation of $\left[\mathrm{PuO}_{2}(\mathrm{HTIPIP})_{2}\left(\mathrm{H}_{2} \mathrm{O}\right)\right]\left[\mathrm{NO}_{3}\right]_{2}$, which incorporates a protonated bidentate TIPIPligand, and $\left[\mathrm{PuO}_{2}(\mathrm{TPIP})(\mathrm{HTPIP})\left(\mathrm{NO}_{3}\right)\right]$, where the protonated HTPIP ligand is bound in a monodentate fashion. Finally a mixed $\mathrm{U}(\mathrm{VI}) / \mathrm{Pu}(\mathrm{VI})$ compound, $\left[\left(\mathrm{UO}_{2} / \mathrm{PuO}_{2}\right)(\mathrm{TPIP})(\mathrm{HTPIP})\left(\mathrm{NO}_{3}\right)\right]$, is reported. All these actinyl complexes remain in the + VI oxidation state in solution over several weeks. The resultant complexes have been characterized using a combination of X-ray structural studies, NMR, optical, and
\end{abstract}


vibrational spectroscopies and electrospray ionization mass spectrometry. The influence of the R-group $\left(\mathrm{R}=\right.$ phenyl or $\left.{ }^{i} \mathrm{Pr}\right)$ on the nature of the complex is discussed with the help of DFT studies.

\section{Introduction}

A fundamental understanding of plutonium chemistry is imperative in order to make much needed progress in the processing, separating and storage of spent nuclear fuel waste, environmental remediation and prediction of its long-term chemical and migratory behavior. ${ }^{1}$ This goal however, is hindered by the high radiotoxicity of plutonium leading to radiolysis reactions and its rich solution chemistry with four easily accessible oxidation states that can simultaneously co-exist in aqueous solution (III, IV, V and VI). ${ }^{1}$ The +IV oxidation state is the most stable under the majority of nitric acid aqueous conditions, meaning that numerous studies have reported the complexation of this cation with various organic ligands. Concerning the hexavalent cation, the chemistry of the lighter uranyl moiety has been studied in great detail, ${ }^{2}$ yet the coordination chemistry of plutonyl compounds is still in its infancy. Most of the studies concern the coordination chemistry of plutonyl(VI) with chelating O-donor ligands such as tetramethyl-3oxa-glutaramide, pyrolidone, triphenylphosphine ${ }^{3,4}$, quinolinic or dipicolinic acid..$^{5,6,7,8,9}$

Polydentate oxygen donor ligands, containing carbonyl, amide or phosphoryl groups have been widely studied in actinide chemistry to better understand the speciation and the reactivity of actinide cations. These ligands have been also considered for use in liquid-liquid extraction processes. Indeed, monoamides (or $N, N$-dialkylamides) are considered as alternatives to the neutral extractant TBP due to their ability to extract uranyl(VI) from nitric acid ${ }^{10,11,12,13}$, and organophosphorus extractants have proven to be interesting molecules that have been considered in several liquid-liquid extraction processes such as TALKSPEAK ${ }^{14,15}$, PUREX $^{16}$ and TRUEX ${ }^{17}$. Among these ligands, imidodiphosphinate molecules are interesting because of their great flexibility that allows the complexation of a large number of cations with different oxidation states and various ionic radii ${ }^{18}$. Concerning tetravalent actinides, one report has described the reaction of U(IV) or Th(IV) with potassium TetraPhenyl ImidodiPhosphinate (KTPIP-) and 

Regarding coordination with actinyls, previous studies by us have reported reactions of NaTPIP with uranyl(VI) and neptunyl(V) or (VI) leading to discrete monomeric, dimeric and, for uranyl, trimeric complexes. ${ }^{20,21,22}$ In the trimetallic $\left[\mathrm{UO}_{2}(\mathrm{TPIP})_{2}\right]_{3}$ complex, each $\mathrm{U}(\mathrm{VI})$ ion is orthogonally connected to its neighbor via intramolecular uranium-oxo interactions which have been shown to persist in organic solution. Remarkably, the TPIP- ligand is able to oxidize $\mathrm{NpO}_{2}(\mathrm{~V})$ to $\mathrm{Np}(\mathrm{VI})$ when $\mathrm{Ph}_{3} \mathrm{PO}$ is added in organic solutions. The resultant $\mathrm{NpO}_{2}(\mathrm{VI})$ complex appears to be stable with respect to reduction and disproportionation in solution as monitored over 9 months. Similarly, this ligand facilitates the oxidation of $\mathrm{UO}_{2}(\mathrm{~V})$ to $\mathrm{UO}_{2}(\mathrm{VI})^{23}$. Furthermore, multinuclear NMR and emission spectroscopies strongly suggest the presence of a mixed $\mathrm{UO}_{2}(\mathrm{VI})-\mathrm{NpO}_{2}(\mathrm{VI})$ solution species that may be assembled by actinyl-oxo interactions. Importantly, such actinide-oxo interactions have been proposed to be key in facilitating electron transfer in the enzymatic bioreduction of uranyl ${ }^{24,25}$ and also are thought to affect the non-optimal extraction of neptunyl in the PUREX process. ${ }^{26}$

We report here the coordination chemistry and spectroscopy of TPIP(TetraPhenylImidodiPhosphinate, TPIP-) and its related counterpart with peripheral iso propyl groups (TetraIsoPropylImidodiPhosphinate, TIPIP-) which has not yet been studied with respect to actinide chemistry with $\mathrm{Pu}(\mathrm{IV}), \mathrm{Pu}(\mathrm{VI})$ and mixed $\mathrm{Pu}(\mathrm{VI})-\mathrm{U}(\mathrm{VI})$ metal systems. The formula of these two ligands under their protonated neutral form, HTPIP and HTIPIP, are reported in Figure 1. The anionic form of the ligand is obtained by deprotonation of the nitrogen atom. Four different new plutonium complexes are described: two for $\mathrm{Pu}(\mathrm{IV}),\left[\mathrm{Pu}(\mathrm{TPIP})_{3}\left(\mathrm{NO}_{3}\right)\right](\mathbf{1})$ and $\left[\mathrm{Pu}(\mathrm{TIPIP})_{2}\left(\mathrm{NO}_{3}\right)_{2}\right]+\left[\mathrm{Pu}(\mathrm{TIPIP})_{3}\left(\mathrm{NO}_{3}\right)\right](\mathbf{2})$, in which the plutonium ion remains in the +IV oxidation state, and two others for $\mathrm{Pu}(\mathrm{VI})$, $\left[\mathrm{PuO}_{2}(\mathrm{TPIP})(\mathrm{HTPIP})\left(\mathrm{NO}_{3}\right)\right]$ (3) and $\left[\mathrm{PuO}_{2}(\mathrm{HTIPIP})_{2}\left(\mathrm{H}_{2} \mathrm{O}\right)\right]\left[\mathrm{NO}_{3}\right]_{2}$ (4). Finally a mixed U(VI)/Pu(VI) compound, $\left[\left(\mathrm{UO}_{2} / \mathrm{PuO}_{2}\right)(\mathrm{TPIP})(\mathrm{HTPIP})\left(\mathrm{NO}_{3}\right)\right]$ (5), isostructural to $\mathbf{3}$, is reported. The different complexes are gathered in Figure 1. The resultant complexes have been characterized using a combination of X-ray structural studies, NMR, optical, and vibrational spectroscopies and electrospray ionization mass spectrometry. The comparison of the different structures coupled with DFT calculations 
allows conclusions concerning the influence of the R-group $\left(\mathrm{R}=\right.$ phenyl or $\left.{ }^{i} \mathrm{Pr}\right)$ on the nature of the structure.

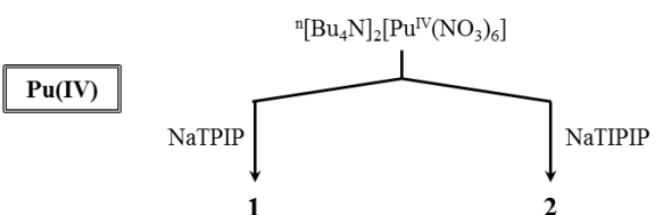

$\left[\mathrm{Pu}^{\mathrm{IV}}(\mathrm{TPIP})_{3}\left(\mathrm{NO}_{3}\right)\right] \quad\left[\mathrm{Pu}^{\mathrm{IV}}(\mathrm{TIPIP})_{2}\left(\mathrm{NO}_{3}\right)_{2}\right]+\left[\mathrm{Pu}^{\mathrm{IV}}(\mathrm{TIPIP})_{3}\left(\mathrm{NO}_{3}\right)\right]$

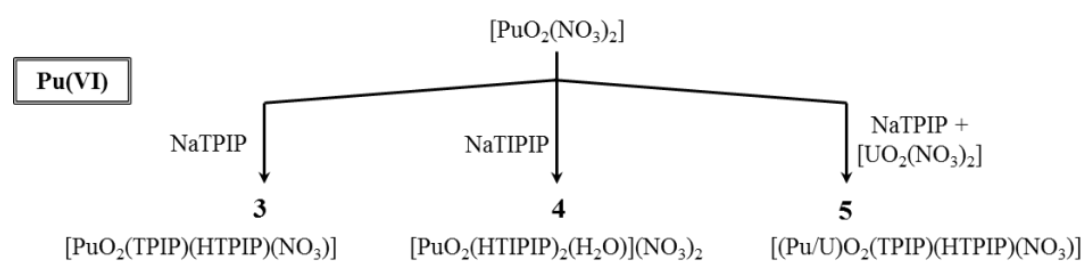

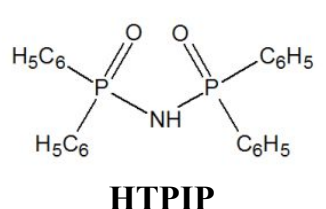

HTPIP

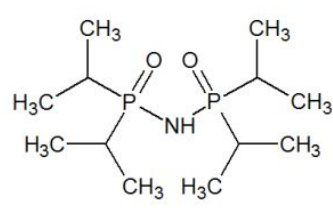

HTIPIP

Figure 1 - Reactions of $\mathrm{Pu}(\mathrm{IV})$ (at the top) and $\mathrm{Pu}(\mathrm{VI})$ (at the bottom) with TPIP- and TIPIP- ligands.

\section{Experimental}

Warning! The ${ }^{239+240} \mathrm{Pu}$ used during the course of this research is a high specific activity $\alpha$ emitting radionuclide. Research with this atom should only be undertaken in an appropriate radiochemical or nuclear facility. Experimental research was undertaken at CEA, Marcoule. All manipulations were undertaken in a regular air atmosphere negative pressure glove box. Multiple containment methods were employed for all spectroscopic and structural characterizations.

\section{Synthetic details}

Chemicals - $\mathrm{Pu}(\mathrm{IV})$ solution is prepared dissolving the corresponding oxide, $\mathrm{PuO}_{2}$, in concentrated $\mathrm{HNO}_{3}$ in glove box. It is then purified by fixation on a DOWEX anion exchange resin at 7 mol.L $\mathrm{L}^{-1} \mathrm{HNO}_{3}$ and elution with 0.5 mol.L $\mathrm{L}^{-1} \mathrm{HNO}_{3}$. Oxidation state and concentration of the actinide solutions were checked by UV-vis spectrophotometry. 
Preparation of ligands NaTPIP and NaTIPIP - NaTPIP was prepared according to literature procedures ${ }^{18,27}$. The NaTIPIP synthesis required the preparation of the ${ }^{i} \operatorname{Pr}_{2} \mathrm{P}(\mathrm{O}) \mathrm{NHP}(\mathrm{O})^{i} \operatorname{Pr}_{2}$ precursor, which was prepared according to a modified literature procedure ${ }^{18}$. To a methanol solution of ${ }^{i} \mathrm{Pr}_{2} \mathrm{P}(\mathrm{O}) \mathrm{NHP}(\mathrm{O}){ }^{i} \operatorname{Pr}_{2}(1.282 \mathrm{~g}, 4.557 \mathrm{mmol})$, a methanol solution of $\mathrm{NaOH}$ was added $(0.177 \mathrm{~g}, 4.415$ mmol) and the reaction mixture was left overnight. All volatiles were removed under vacuum before the crude product was purified via washing with hot toluene and dried in vacuo. Yield: $0.957 \mathrm{~g}, 3.154 \mathrm{mmol}$, $69 \% .{ }^{1} \mathrm{H}$ NMR $(400 \mathrm{MHz}, \mathrm{MeOD}, 290 \mathrm{~K}): \delta 1.82\left(\mathrm{~m}, 4 \mathrm{H}, \mathrm{CH}_{3} \mathrm{CH}\right), 1.13\left(\mathrm{dt}, \mathrm{CH}_{3} \mathrm{CH}, 24 \mathrm{H}\right)$ ppm. ${ }^{31} \mathrm{P}\left\{{ }^{1} \mathrm{H}\right\}$ NMR (400 MHz, MeOD, $\left.290 \mathrm{~K}\right): \delta 35.88$ (s). Accurate ESI-MS +ve $(\mathrm{m} / \mathrm{z})$ : Calc: 304.1566. Found: $304.1563\left(\mathrm{C}_{12} \mathrm{H}_{28} \mathrm{NNaO}_{2} \mathrm{P}_{2} \mathrm{H}^{+}\right)$.

Preparation of plutonium precursors. A plutonium(VI) nitrate solution was prepared by addition of 10 equivalents $(27.3 \mathrm{mg}, 0.22 \mathrm{mmol})$ of $\mathrm{AgO}$ to a $\mathrm{Pu}(\mathrm{IV})$ nitrate solution $\left(0.022 \mathrm{mmol},\left[\mathrm{HNO}_{3}\right]=1 \mathrm{M}, \mathrm{mPu}\right.$ $=5.3 \mathrm{mg}$ ). The reaction mixture was left overnight. UV-vis spectroscopy was used to check complete oxidation to $\mathrm{Pu}(\mathrm{VI}) .10$ equivalents of $\mathrm{HCl}(0.22 \mathrm{mmol}, \mathrm{m}=7.9 \mathrm{mg})$ were added to precipitate the $\mathrm{Ag}$ ions. The $\mathrm{AgCl}$ solid was separated by centrifugation. A UV-vis spectrum was collected to check the $\mathrm{Pu}(\mathrm{VI})$ oxidation state.

$\left[{ }^{n} \mathrm{Bu}_{4} \mathrm{~N}\right]_{2}\left[\mathrm{Pu}\left(\mathrm{NO}_{3}\right)_{6}\right]$ was prepared according to a literature procedure. ${ }^{28}$ Synthesis of $\left[\mathrm{Pu}(\mathrm{TPIP})_{3}\left(\mathrm{NO}_{3}\right)\right](\mathbf{1})$. NaTPIP $(36.8 \mathrm{mg}, 0.084 \mathrm{mmol})$ was suspended in ethanol $(500 \mu \mathrm{L})$ and added to a green solution of $\left[{ }^{n} \mathrm{Bu}_{4} \mathrm{~N}\right]_{2}\left[\mathrm{Pu}\left(\mathrm{NO}_{3}\right)_{6}\right](23.0 \mathrm{mg}, 0.021 \mathrm{mmol})$ in ethanol $(1500 \mu \mathrm{L})$ with stirring. The solution became colorless and a pale pink precipitate was formed. After stirring for 2 hours, 
the precipitate was separated by centrifugation and dissolved in THF (500 $\mu \mathrm{L})$ to give a pink solution. The THF solution was layered with hexane. Standing overnight yielded red-brown crystals. Synthesis of $\left[\mathrm{Pu}(\mathrm{TIPIP})_{2}\left(\mathrm{NO}_{3}\right)_{2}\right]+\mathrm{Pu}(\mathrm{TIPIP})_{3}\left(\mathrm{NO}_{3}\right)$ (2). NaTIPIP $(12.7 \mathrm{mg}, 0.042 \mathrm{mmol})$ was dissolved in ethanol $(500 \mu \mathrm{L})$ and added to a green solution of $\left[{ }^{n} \mathrm{Bu}_{4} \mathrm{~N}\right]_{2}\left[\mathrm{Pu}\left(\mathrm{NO}_{3}\right)_{6}\right](23.0 \mathrm{mg}, 0.021 \mathrm{mmol})$ in ethanol $(1500 \mu \mathrm{L})$ with stirring to yield a brown solution. Evaporation of solvent under ambient conditions led to the appearance of an orange-brown polycrystalline solid.

Synthesis of $\left[\mathrm{PuO}_{2}(\mathrm{TPIP})(\mathrm{HTPIP})\left(\mathrm{NO}_{3}\right)\right]$ (3). NaTPIP $(18.4 \mathrm{mg}, 0.042 \mathrm{mmol})$ was suspended in ethanol $(500 \mu \mathrm{L})$ and added to a plutonyl nitrate $(0.021 \mathrm{mmol}, \mathrm{mPu}=5.0 \mathrm{mg})$ solution with stirring. A pale brown-yellow solid precipitated immediately. The reaction mixture was stirred for one hour. The precipitate was separated by centrifugation, dissolved in the minimum volume of $\mathrm{CH}_{2} \mathrm{Cl}_{2}$ and layered with hexane. Standing overnight yielded orange-brown crystals.

Synthesis of $\left[\mathrm{PuO}_{2}(\mathrm{HTIPIP})_{2}\left(\mathrm{H}_{2} \mathrm{O}\right)\right]\left[\mathrm{NO}_{3}\right]_{2}$ (4). NaTIPIP (12.7 mg, $\left.0.042 \mathrm{mmol}\right)$ was dissolved in ethanol $(500 \mu \mathrm{L})$ and added to a plutonyl nitrate solution $(0.021 \mathrm{mmol}, \mathrm{mPu}=5.0 \mathrm{mg})$ with stirring. The solution color became slightly paler. Evaporation of solvent under ambient conditions led to the growth of orangebrown crystals.

Synthesis of $\left[(\mathrm{Pu}, \mathrm{U}) \mathrm{O}_{2}(\mathrm{TPIP})(\mathrm{HTPIP})\left(\mathrm{NO}_{3}\right)\right](5) . \mathrm{UO}_{2}\left(\mathrm{NO}_{3}\right)_{2} \cdot 6 \mathrm{H}_{2} \mathrm{O}(10.5 \mathrm{mg}, 0.021 \mathrm{mmol})$ was added to a plutonyl nitrate solution $(0.021 \mathrm{mmol}, \mathrm{mPu}=5.0 \mathrm{mg})$ to give a yellow-brown solution. NaTPIP (36.8 $\mathrm{mg}, 0.084 \mathrm{mmol})$ suspended in $\mathrm{EtOH}(500 \mu \mathrm{L})$ was then added with stirring. A pale yellow precipitate formed immediately. After stirring for one hour, the solid was isolated by centrifugation, dissolved in the minimum volume of $\mathrm{CH}_{2} \mathrm{Cl}_{2}$ and layered with hexane. Standing overnight yielded yellow crystals.

\section{Crystallography}

Data Collection. X-ray data for compounds 1, 3, 4 and 5 were collected at room temperature using a Mo$\mathrm{K}_{\alpha}$ radiation on a Nonius four circle diffractometer equipped with a Bruker Apex2 detector. Data were measured using Apex2 suite of programs. X-ray data were processed and reduced using CrysAlisPro suite of programs. Absorption correction was performed using empirical methods based upon symmetry- 
equivalent reflections combined with measurements at different azimuthal angles ${ }^{29,30,31}$. The crystal structures were solved and refined against all $F^{2}$ values using the SHELXL and Olex2 suite of programs. ${ }^{32,33}$ All the atoms were refined anisotropically. Hydrogen atoms were placed in calculated positions refined using idealized geometries (riding model) and assigned fixed isotropic displacement parameters. Phenyl groups were sometimes disordered and modelled over two different positions. The C$\mathrm{C}$ and C-P distances were restrained using SADI and DFIX commands. The atomic displacement parameters were also restrained using SIMU and RIGU commands. The BUMP command was used to avoid hydrogen short contacts. The occupancies used in the mixed metal compound (5) were set using UV-vis spectroscopy and were not refined. The $\mathrm{U}$ and $\mathrm{Pu}$ atoms were constrained to have the same adps and to be in the same position using EADP and EXYZ commands. The crystallographic details of the different structures are given in Table 1. The main distances of the structures are presented in Table S1 (1), S4 (3), S6 (4) and S8 (5) of the supporting information. CCDC 1895585 (1), 1895586 (3), 1895588 (4) and 1895587 (5) contain the supplementary crystallographic data for this paper.

Table 1 - Crystallographic information for compounds $1,3,4$ and 5.

\begin{tabular}{|c|c|c|c|c|}
\hline & 1 & 3 & 4 & 5 \\
\hline Crystal colour & Red & Brown & Brown & Yellow \\
\hline Crystal size $(\mathrm{mm})$ & $0.6 \times 0.1 \times 0.03$ & $0.15 \times 0.1 \times 0.06$ & $0.5 \times 0.1 \times 0.03$ & $0.15 \times 0.1 \times 0.06$ \\
\hline Crystal system & Monoclinic & Triclinic & Monoclinic & Triclinic \\
\hline Space group & $\mathrm{P} 2_{1} / \mathrm{c}$ & P-1 & $\mathrm{P} 2_{1} / \mathrm{c}$ & P-1 \\
\hline$Z$ & 8 & 2 & 4 & 2 \\
\hline$a(\AA)$ & $29.9395(5)$ & $11.0646(1)$ & $16.8978(3)$ & $11.0294(2)$ \\
\hline$b(\AA)$ & $20.7556(3)$ & $11.9183(2)$ & 17.9212(3) & $11.9196(2)$ \\
\hline$c(\AA)$ & $23.6410(4)$ & $19.0645(2)$ & $14.5044(3)$ & 19.1764(3) \\
\hline$\alpha\left(^{\circ}\right)$ & 90 & $82.825(1)$ & 90 & $82.997(1)$ \\
\hline$\beta\left(^{\circ}\right)$ & $103.752(2)$ & $89.572(1)$ & $102.857(2)$ & $89.713(1)$ \\
\hline$r\left({ }^{\circ}\right)$ & 90 & $73.630(1)$ & 90 & $73.008(1)$ \\
\hline$V\left(\AA^{3}\right)$ & $14269.7(4)$ & $2392.23(6)$ & $4282.2(1)$ & $2391.75(6)$ \\
\hline Density $\left(\mathrm{Mg} \cdot \mathrm{m}^{-3}\right)$ & 1.480 & 1.628 & 1.546 & 1.619 \\
\hline Wavelength $(\AA)$ & 0.71073 & 0.71073 & 0.71073 & 0.71073 \\
\hline Temperature $(\mathrm{K})$ & $293(2)$ & $293(2)$ & $293(2)$ & $293(2)$ \\
\hline$\mu(\mathrm{Mo}-\mathrm{K} \alpha)\left(\mathrm{mm}^{-1}\right)$ & 1.118 & 1.569 & 1.746 & 3.383 \\
\hline $2 \theta$ range $\left({ }^{\circ}\right)$ & 3.42 to 52.746 & 3.944 to 52.742 & 3.668 to 52.736 & 3.602 to 52.74 \\
\hline Reflns collected & 177348 & 46392 & 64804 & 40039 \\
\hline $\begin{array}{l}\text { Independent reflns } \\
\left(R_{\text {int }}\right)\end{array}$ & $29079(0.0486)$ & $9762(0.0216)$ & $8734(0.0196)$ & $9759(0.0197)$ \\
\hline L.S. parameters, $p$ & 1672 & 669 & 440 & 666 \\
\hline No. of restraints, $r$ & 864 & 228 & 47 & 238 \\
\hline$R 1(F)^{\mathrm{a}} I>2.0 \sigma(I)$ & 0.0411 & 0.0239 & 0.0219 & 0.0216 \\
\hline$w R 2\left(F^{2}\right),{ }^{\mathrm{a}}$ all data & 0.0917 & 0.0548 & 0.0643 & 0.0467 \\
\hline$S\left(F^{2}\right),{ }^{\mathrm{a}}$ all data & 1.028 & 1.001 & 1.109 & 1.083 \\
\hline
\end{tabular}

${ }^{\mathrm{a}} R l(F)=\Sigma\left(\left|F_{o}\right|-\left|F_{c}\right|\right) / \Sigma\left|F_{o}\right| ;[\mathrm{b}] w R^{2}\left(F^{2}\right)=\left[\Sigma w\left(F_{o}{ }^{2}-F_{c}{ }^{2}\right)^{2} / \Sigma w F_{o}{ }^{4}\right]^{1 / 2} ;[\mathrm{c}] S\left(F^{2}\right)=\left[\Sigma w\left(F_{o}{ }^{2}-F_{c}{ }^{2}\right)^{2} /(n+r-p)\right]^{1 / 2}$ 
Mass Spectrometry - Mass spectrometric measurements were recorded in positive ionization mode using a Bruker Esquire-LC quadrupole ion trap equipped with an electrospray interface that was specifically set up in a glove box ${ }^{34}$. The experimental conditions were: drying gas $\left(\mathrm{N}_{2}\right) 5 \mathrm{~L} / \mathrm{min}$, nebulizer gas 5 psi, temperature $250^{\circ} \mathrm{C}$, ion spray voltage of $4000 \mathrm{~V}$, cap exit offset of $60 \mathrm{~V}$, skimmer 1 of 20-90 V, skimmer 2 of constant $10 \mathrm{~V}$, trap drive 90 . Spectra were acquired over a mass range of $\mathrm{m} / \mathrm{z} 45-2200$. A syringe infusion pump (Cole Palmer) delivered samples at $90 \mu \mathrm{L} / \mathrm{h}$ to the electrospray source. Helium gas was used as the buffer gas in the trap to improve trapping efficiency and as collision gas for fragmentation experiments. All samples were diluted $1 / 1000^{\text {th }}$ in acetonitrile before analysis. Assignments of the mass peaks of the main species were made by comparison with isotopic pattern calculated using the software DataAnalysis 4.0 (see figure 2 as example). Plutonium isotopic composition was the following: $0.08 \%$ ${ }^{238} \mathrm{Pu}, 80.591 \%{ }^{239} \mathrm{Pu}, 17.147 \%{ }^{240} \mathrm{Pu}, 1.809 \%{ }^{241} \mathrm{Pu}, 0.373 \%{ }^{242} \mathrm{Pu}$, uranium isotopic compositions was $100 \%{ }^{238} \mathrm{U}$.

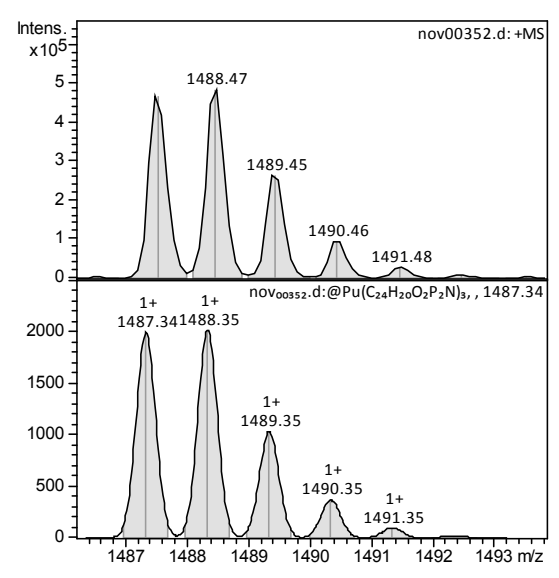

Figure 2 - Experimental and simulated mass peaks of Pu(TPIP) species. Experimental (top) $\left[\mathrm{Pu}(\mathrm{IV})(\mathrm{TPIP})_{3}\right]^{+}$and simulated (bottom peaks).

Raman Spectroscopy - A Jobin-Yvon LabRam Raman 242 spectrometer was used in conjunction with a nuclearized superhead (Optique Peter, Lyon, France) mounted on a support with an objective turret (10×, $20 \times$ and $50 \times)$. A YAG laser $(100 \mathrm{~mW}, 532 \mathrm{~nm})$ was used with a variable filter to provide low-excitationbeam power levels. The superhead was mounted in a glove box, while the Raman spectrometer and laser 
were installed outside with a fiber-optic signal transmission line. The microscope objective used for single crystal analyses was $20 \times$.

UV-visible Spectroscopy - The actinide solutions were analyzed by UV - vis absorption spectroscopy using a Cary 5000 UV spectrophotometer (Agilent) between 350 and $900 \mathrm{~nm}$.

Infrared spectroscopy - The solids were analyzed with a dual channel FT-IR spectrophotometer from Bruker optics, equinox 55 equipped with an ATR module enabling solid samples to be examined directly without further preparation.

NMR - Multinuclear NMR spectra of Pu complexes were recorded using a $400 \mathrm{MHz}$ Fourier transform spectrometer (Agilent DD2) equipped with an Agilent two channels 5mm z-gradient probe (“OneNMR probe"). Liquid samples are prepared according to a double containment procedure and a set of dedicated glove-boxes. ${ }^{35}$

DFT - Quantum chemistry calculations were performed at the DFT level of theory with the Gaussian 09 program package. ${ }^{36,37}$ Aqueous solvation effects were taken into account by using an implicit solvation model where the solute is embedded inside a molecular-shape cavity surrounded by a dielectric medium. The Integral Equation Formalism Polarizable Continuum Model (IEFPCM) was used as implemented in Gaussian 09. The B3LYP functional was employed.

The geometries of the plutonium complexes were optimized in the gas phase using $\mathrm{Pu}(\mathrm{IV})$ large-core relativistic effective core potentials (RECP) developed in the Stuttgart/Cologne group together with the accompanying $(7 \mathrm{~s} 6 \mathrm{p} 5 \mathrm{~d} 2 \mathrm{f}) /[5 \mathrm{~s} 4 \mathrm{p} 4 \mathrm{~d} 2 \mathrm{f}]$ basis set to describe the valence electron density. ${ }^{38}$ For other atoms, the 6-31G* basis set was used. Single-point energy calculations were performed in the presence of a solvent model corresponding to water using a def2-TZVP basis set for other atoms. ${ }^{39}$ 
For each $\mathrm{Pu}(\mathrm{IV})$ complex, different initial configurations were generated and the most stable configuration was selected for computing the relative energy differences. Thermochemistry values $(\Delta \mathrm{G}$ and $\Delta \mathrm{H})$ were deduced from a frequency calculation on each structure.

\section{Results}

The precursor complex $\left[{ }^{n} \mathrm{Bu}_{4} \mathrm{~N}\right]_{2}\left[\mathrm{Pu}\left(\mathrm{NO}_{3}\right)_{6}\right]$ was used as a facile route to prepare an organic soluble $\mathrm{Pu}(\mathrm{IV})$ reagent ${ }^{28}$ that would obviate the use of the acidic conditions that can cause $\mathrm{Pu}(\mathrm{IV})$ hydrolysis in presence of water. The reaction scheme leading to the formation of the different $\mathrm{Pu}(\mathrm{IV})$ compounds is presented in Figure 1. The plutonium(VI) compounds were synthesized using a $\mathrm{Pu}(\mathrm{VI})$ nitrate solution as a starting material (Figure 1).

\section{Compound 1: $\left[\mathrm{Pu}(\mathrm{TPIP})_{3}\left(\mathrm{NO}_{3}\right)\right]$}

At the end of recrystallization, crystals of $\mathbf{1}$ appeared within a colorless gel. The formation of the gel is likely to favor the growth of the crystals conferring some additional diffusion effects. Compound $\mathbf{1}$ was formulated as $\left[\mathrm{Pu}(\mathrm{TPIP})_{3}\left(\mathrm{NO}_{3}\right)\right]$ by single crystal $\mathrm{X}$-ray diffraction (Figure 3 ). The asymmetric unit is composed of two crystallographically different $\left[\mathrm{Pu}(\mathrm{TPIP})_{3}\left(\mathrm{NO}_{3}\right)\right]$ monomers. The $\mathrm{Pu}(\mathrm{IV})$ atoms adopt a distorted dodecahedron coordination geometry $(\mathrm{CN}=8)$ with three bidentate TPIP- ligands and a bidentate nitrate anion. Despite the use of four equivalents of NaTPIP in the reaction, it was not possible to isolate $\left[\mathrm{Pu}(\mathrm{TPIP})_{4}\right]$, although the analogous complexes have been reported for $\mathrm{U}(\mathrm{IV})$ and $\mathrm{Th}(\mathrm{IV})$ in similar conditions. ${ }^{19}$ The smaller ionic radius of $\mathrm{Pu}(\mathrm{IV})(0.96 \AA \mathrm{CN}=8)$ compared to $\mathrm{U}(\mathrm{IV})(1.00 \AA \mathrm{CN}=8)$ and Th(IV) (1.05 $\AA, C N=8)$ is likely to preclude the coordination of four TPIP- ligands because of steric constraints. ${ }^{40}$ Another explanation is the presence of nitrate that could compete with TPIP- complexation. Indeed, single crystals of the U(IV) and Th(IV) compounds were grown in a chloride media while the $\mathrm{Pu}(\mathrm{IV})$ one, here was synthesized in excess of nitrate ions. The addition of some nitrate to the $\mathrm{Th}(\mathrm{IV})$ 
compound synthesis allow the formation of a structure where the Th(IV) is coordinated to three imidodiphosphinates and two nitrates, $\left[\mathrm{Th}\left(\mathrm{Ph}_{2} \mathrm{P}(\mathrm{O}) \mathrm{N}(\mathrm{Pr}) \mathrm{P}(\mathrm{O}) \mathrm{Ph}_{2}\right)_{3}\left(\mathrm{NO}_{3}\right)_{2}\right]^{2+} 41$ indicating that this nitrate/TPIP- competition is quite important. For this system, the chloride complexation is likely a little smaller than the nitrate. The average $\mathrm{Pu}-\mathrm{O}_{\text {ligand }}$ bond length in $\mathbf{1}$ is $2.275 \AA$ compared with $2.37 \AA$ for the $\mathrm{U}-\mathrm{O}_{\text {ligand }}$ bonds in $\left[\mathrm{U}(\mathrm{TPIP})_{4}\right]$, and $2.41 \AA$ for the Th- $\mathrm{O}_{\text {ligand }}$ bonds in $\left[\mathrm{Th}(\mathrm{TPIP})_{4}\right]^{19}$. This trend is consistent with the decreasing 8-fold coordinated ionic radii and less steric effects due to the smaller size of one nitrate ion compare to one organic ligand. The shortening of the $\mathrm{An}-\mathrm{O}_{\text {ligand }}$ bond for the plutonium compound is concomitant with an increase of the O-An-O angles with $71.8^{\circ}, 72.8^{\circ}$ and $77.7^{\circ}$ for $\mathrm{Th}(\mathrm{IV})$, $\mathrm{U}(\mathrm{IV})$ and $\mathrm{Pu}(\mathrm{IV})$ respectively. The comparison of the $\mathrm{P}=\mathrm{O}$ and $\mathrm{P}-\mathrm{N}$ distances with the ones of an uncomplexed TPIP- ligand ${ }^{42}$ reveals an increase of the complexed $\mathrm{P}=\mathrm{O}$ bonds from 1.495(7) to 1.522(4) $\AA$, and a decrease of the P-N distances from 1.589(9) to 1.576(4) $\AA$ with complexation (see table S1 of the supporting information). This evolution results in the electronic delocalization and a greater contribution of the charge-separated resonance form in the complexes compared to the uncomplexed ligand (Figure S23 of the supporting information). The P-C bonds are equivalent between the uncoordinated and coordinated ligands indicating that the charge delocalization from the phenyl group does not change upon complexation. With a $\mathrm{N}-\mathrm{P}=\mathrm{O}$ charge delocalization fluctuating with complexation, an evolution of the $\mathrm{Ph}$ $\mathrm{P}=\mathrm{O}$ charge delocalization could be also expected. This property is all the more expected since some differences can be observed in the bond distances of the uncomplexed TPIP- 42 structures and uncomplexed TIPIP- 18 one with an average of $1.505(4)$ and $1.479(2) \AA$ respectively for $\mathrm{P}=\mathrm{O}$ distances and 1.787(5) and 1.807(3) A respectively the for P-C bonds. This above evolution of the ligand distances ( $\mathrm{P}-\mathrm{N}$ and $\mathrm{P}=\mathrm{O}$ ) with complexation can be also observed in other imidophosphinate structures, $\left[\mathrm{Th}\left(\mathrm{Ph}_{2} \mathrm{P}(\mathrm{O}) \mathrm{N}\left(\mathrm{Pr}^{\mathrm{i}}\right) \mathrm{P}(\mathrm{O}) \mathrm{Ph}_{2}\right)_{3}\left(\mathrm{NO}_{3}\right)_{2}\right]^{2+41},\left[\mathrm{U}(\mathrm{TPIP})_{4}\right]$ and $\left[\mathrm{Th}(\mathrm{TPIP})_{4}\right]^{19}$. 
Figure 3-3D and 2D views of the molecular structure of $\mathbf{1}$. $\mathrm{H}$ atoms are omitted for clarity. Ellipsoids are drawn at the $40 \%$ probability level.

The consideration of the $\mathrm{P}=\mathrm{O}$ and $\mathrm{P}-\mathrm{N}$ distances for the different actinide-TPIP- structures shows a very narrow distribution centered on $1.518( \pm 0.004) \AA$ and $1.580( \pm 0.004) \AA$ respectively. These equivalent distances indicate the weak influence of the metallic cation nature, the $\mathrm{CN}$ and the number of ligands within the coordination sphere on the ligand distances. On the contrary, the P-N-P angle varies between 119 and $129^{\circ}$ and the O-P-N ring chelate deviation from planarity evolved between 0 and $15^{\circ}$ indicating an important flexibility of the ligand that masks any distance evolution between the different complexes.

The Raman and infrared spectra of the crystals were collected and compared to that of NaTPIP. The spectra as well as suggested band assignments are presented in the supporting information (Figure S6 and Table S2). The band attributions were made based on the Raman signature of phenyl groups ${ }^{43}$ and several vibrational studies of imidophosphinate complexes ${ }^{41,44}$. A comparison of the Raman spectra of $\mathbf{1}$ and NaTPIP shows that the spectra are similar besides shifts of some bands with complexation. The hypothesis is that the $\mathrm{P}=\mathrm{O}$ stretching of the free TPIP- is superimposed (the peak appears as a shoulder) 
with the phenyl signature at $1162 \mathrm{~cm}^{-1}$. The frequency of this band decreases with complexation and is likely to be observed at $1053 \mathrm{~cm}^{-1}$. The infrared analysis is useful to confirm the presence of coordinated nitrate ions (small band near $1390 \mathrm{~cm}^{-1}$ as well as the shoulder around $1056 \mathrm{~cm}^{-1}$ ), the signature of which is not clearly observed in the Raman spectrum because of superposition with bands of the phenyl groups.

The high symmetry of 1 gives simple ${ }^{1} \mathrm{H}$ and ${ }^{31} \mathrm{P}\left\{{ }^{1} \mathrm{H}\right\}$ NMR spectra that are easily assignable, allowing a detailed study. The ${ }^{1} \mathrm{H}$ NMR spectrum of $\mathbf{1}$ after dissolution in deuterated THF (Figure S3 of the SI) shows three multiplets at 6.75 (ortho), 6.58 (para) and 6.39 (meta) ppm that correspond to the three aromatic proton environments in contrast to the ${ }^{1} \mathrm{H}$ NMR spectrum of the uncoordinated ligand, which exhibits two complex multiplets at 7.09 (ortho) and 6.45 (para+meta) ppm. All the resonances were assigned by gCOSY and CIGAR- ${ }^{31} \mathrm{P}-{ }^{1} \mathrm{H}$ NMR experiments. The ${ }^{31} \mathrm{P}\left\{{ }^{1} \mathrm{H}\right\}$ NMR spectrum of $\mathbf{1}$ shows a single peak at $-51.0 \mathrm{ppm}$ with a significant shift from unbound ligand at $13.4 \mathrm{ppm}$ (see Figure S2 of the SI). ${ }^{31} \mathrm{P}$ DOSY experiments were undertaken to establish whether there was oligomerization in solution as observed previously for the uranyl(VI) TPIP derivatives of this ligand. The complex in THF has a diffusion coefficient of $12 \pm 1 \times 10^{-10} \mathrm{~m}^{2} \cdot \mathrm{s}^{-1}$ compared to $7 \pm 1 \times 10^{-10} \mathrm{~m}^{2} \cdot \mathrm{s}^{-1}$ for NaTPIP. With the same order of magnitude, these values indicate that there is no oligomerization in solution given the relative molecular weight differences. These analyses suggest conservation of the structure in solution after dissolution of the crystals.

To complement the characterization, an ESI-MS investigation of compounds in solution was performed. This technique is known to be used in combination with traditional solution chemistry techniques to investigate metal-ligand interactions ${ }^{45,46}$. Actinide species have been studied by ESI-MS since the early 1990's where the use of electrospray mass spectrometry was utilized for the analysis of various elements including $\mathrm{U}(\mathrm{VI})^{47,48}, \mathrm{Th}(\mathrm{IV})^{49,50,51,52,53,54,55,56,57}, \mathrm{Am}(\mathrm{III})^{34,58,59,60,61,62,63}, \mathrm{~Np}$ and $\mathrm{Pu}$ in different oxidation states $64,65,66,67,68,69,70$. The publications range from species identification to specific interest in the chemistry of the f-elements ${ }^{59,50,71}$ through the investigation of competitive interactions ${ }^{54}$. Additionally, a number of studies have included the use of ESI-MS to investigate the gas phase behavior 
of $\mathrm{UO}_{2}{ }^{+}, \mathrm{UO}_{2}{ }^{2+}, \mathrm{PuO}_{2}{ }^{+}$and $\mathrm{PuO}_{2}{ }^{2+55,72,65,66,67,73,74,75,76,77} \mathrm{Pu}(\mathrm{III})^{61,59,60}, \mathrm{Pu}(\mathrm{IV})$ gas phase behavior ${ }^{59,78}$ and Rios et al. reported the gas phase reduction of $\mathrm{PuO}_{2}{ }^{2+}$ to $\mathrm{Pu}(\mathrm{V})$ and $\mathrm{Pu}(\mathrm{IV})$ followed by ESI-MS ${ }^{67}$. The ESI-MS spectra in positive ionisation mode of 1 after dissolution of some crystals in THF and $1 / 1000^{\text {th }}$ dilution in $\mathrm{CH}_{3} \mathrm{CN}$ are reported in the SI (Figure S4 and S5) . The main peak corresponds to $\left[\mathrm{Pu}(\mathrm{TPIP})_{3}\right]^{+}$ $(\mathrm{m} / \mathrm{z}=1488.5)$. This ion is stable when increasing the skimmer voltage. Its fragmentation spectrum $\left(\mathrm{MS}^{2}\right)$ leads to loss of one TPIP- ligand associated with the reduction of $\mathrm{Pu}(\mathrm{IV})$ to $\mathrm{Pu}(\mathrm{III})$, resulting in a $\left[\mathrm{Pu}(\mathrm{TPIP})_{2}\right]^{+}$species $($at $\mathrm{m} / \mathrm{z}=1071.4)$. The $\mathrm{MS}^{3}$ spectra of $\left[\mathrm{Pu}(\mathrm{TPIP})_{2}\right]^{+}$leads to a fragmentation of the ligand by loss of phenyl or $\mathrm{PO}(\mathrm{Ph})_{2}$ groups. The reduction of $\mathrm{Pu}(\mathrm{IV})$ to $\mathrm{Pu}(\mathrm{III})$ is not surprising and has already been observed by Gong et al. during the collision induced dissociation experiments of $\mathrm{Pu}(\mathrm{TMDGA})_{3}{ }^{4+}$ species $^{55}$. The presence of one main stable ion $\left[\mathrm{Pu}(\mathrm{TPIP})_{3}\right]^{+}$is consistent with the $\left[\mathrm{Pu}(\mathrm{TPIP})_{3}\left(\mathrm{NO}_{3}\right)\right]$ structure. Indeed during the solubilisation / desolvation and ionisation step, a positive ion is formed by release of the nitrate moiety, and in the gas phase, the metal-nitrate interactions are weakened. ${ }^{79,80}$

All the experiments are in agreement and indicate the formation of a quite stable complex, $\left[\mathrm{Pu}(\mathrm{TPIP})_{3}\left(\mathrm{NO}_{3}\right)\right]$, in both the solid and liquid phases whose UV-vis spectrum was additionally registered to confirm the $+\mathrm{IV}$ oxdation state of Pu (see Figure S1 of the SI).

\section{Compound 2: $\left[\mathrm{Pu}(\mathrm{TIPIP})_{2}\left(\mathrm{NO}_{3}\right)_{2}\right]+\left[\mathrm{Pu}(\mathrm{TIPIP})_{3}\left(\mathrm{NO}_{3}\right)\right]$}

Despite several attempts, it was not possible to grow crystals of sufficient quality for single crystal XRD so other analytical techniques were required to identify compound $\mathbf{2}$. Compound $\mathbf{2}$ dissolved in deuterated $\mathrm{CDCl}_{3}$ gives sharp signals in both the ${ }^{1} \mathrm{H}$ and ${ }^{31} \mathrm{P}\left\{{ }^{1} \mathrm{H}\right\}$ NMR spectra (Figure 4). Two major species can be identified in the ${ }^{31} \mathrm{P}\left\{{ }^{1} \mathrm{H}\right\}$ NMR spectra at 59.6 and $49.2 \mathrm{ppm}$ in approximately a 3:1 ratio, shifted from NaTIPIP at $36.4 \mathrm{ppm}$. CIGAR ${ }^{31} \mathrm{P}-{ }^{1} \mathrm{H}$ and PSYCHE-TOCSY $2 \mathrm{D}{ }^{1} \mathrm{H}$ NMR experiments aided the assignment of the ${ }^{1} \mathrm{H}$ and ${ }^{31} \mathrm{P}\left\{{ }^{1} \mathrm{H}\right\}$ NMR spectra (see Figure S8 of the SI).). Two complex multiplets at 
2.24 and $1.19 \mathrm{ppm}$ in a 1:6 ratio correlate with the signal at $59.7 \mathrm{ppm}$ in the ${ }^{31} \mathrm{P}\left\{{ }^{1} \mathrm{H}\right\} \mathrm{NMR}$ spectrum. Three complex multiplets at 2.07, 0.85 and $0.65 \mathrm{ppm}$ in a 1:3:3 ratio correlate with the signal at $49.2 \mathrm{ppm}$ in the ${ }^{31} \mathrm{P}\left\{{ }^{1} \mathrm{H}\right\}$ NMR spectrum. The two sets of ${ }^{1} \mathrm{H}$ NMR signals occur in approximately 3:1 ratio. This suggests the presence of two separate species, not isomers, in approximately a 3:1 ratio in solution. It is interesting to note that the ${ }^{1} \mathrm{H}$ spectrum of the TIPIP- alone shows two different $\mathrm{CH}_{3}$ chemical shifts. Taking into account that ${ }^{3} \mathrm{~J}_{\mathrm{HP}}=4.8 \mathrm{~Hz}$ and ${ }^{3} \mathrm{~J}_{\mathrm{HH}}=6.9 \mathrm{~Hz}$, equivalent $\mathrm{CH}_{3}$ protons would lead to a doublet of doublets but actually eight peaks are observed instead. This suggests that there is a hindered rotation even in the sodium salt of the TIPIP ligand. In the $\mathrm{Pu}(\mathrm{IV})$ complex 2 , this effect is increased especially in the compound present in the smaller proportion (blue assignments).
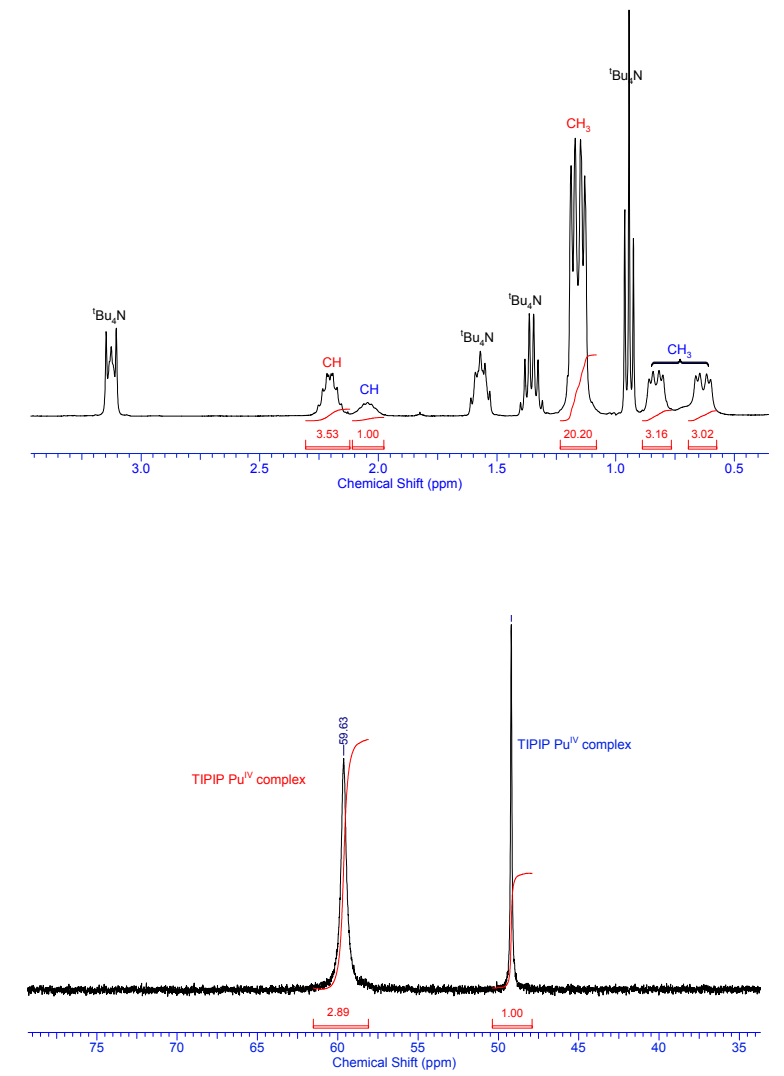

Figure $4-{ }^{1} \mathrm{H}$ (top) and ${ }^{31} \mathrm{P}\left\{{ }^{1} \mathrm{H}\right\}$ (bottom) NMR spectra of 2 in $\mathrm{CDCl}_{3}$ at $290 \mathrm{~K}$ showing the presence of two species in solution (peaks assigned in red and blue). In the ${ }^{1} \mathrm{H}$ NMR spectrum, peaks belonging to ${ }^{\mathrm{n}} \mathrm{Bu}_{4} \mathrm{~N}$ used for the synthesis can be observed. 
The Raman spectrum of $\mathbf{2}$ is presented in Figure S10 of the supporting information and the main bands are reported in Table S3 of the SI and the vibrational spectrum is compared to that of NaTIPIP. For both spectra, the main bands of the $\mathrm{CH}_{3}$ groups of the isopropyl chains can be identified around 885,970 , $1030,1170,1250-1280,1460$ and $3000 \mathrm{~cm}^{-1}$. The bands of 2 are quite difficult to assign due to the presence of a mix of two components. The intense bands around 1036-1048 $\mathrm{cm}^{-1}$, are related to the N-O stretch of the nitrate groups superimposed with the asymmetric stretching of the C-C-C part of the molecule. A medium intensity nitrate band is also observed at $1540 \mathrm{~cm}^{-1}$. The $\mathrm{P}=\mathrm{O}$ stretch of NaTIPIP is attributed to the band at $1095 \mathrm{~cm}^{-1}$. Upon complexation to $\mathrm{Pu}(\mathrm{IV})$, the band frequency is expected to decrease but it is difficult to accurately assign the $\mathrm{P}=\mathrm{O}$ bond without knowing the exact protonation state of the ligand within the mixture of compounds.

The IR spectrum of complex 2 was also recorded and compared to that of NaTIPIP one. The main bands of the $\mathrm{CH}_{3}$ groups of the isopropyl chains can be identified around 890, 1160, 1370, 1460, 3000 $\mathrm{cm}^{-1}$. The presence of nitrate can also be observed in the IR spectrum of 2 (Figure S10 of the SI) with stretches assignable to nitrate at 1517 and $1030 \mathrm{~cm}^{-1}$. However, further assignment proved difficult due to the mixture of complexes present in the isolated bulk solid.

The ESI-MS spectra in positive ionization mode of 2 dissolved in ethanol and $1 / 1000^{\text {th }}$ diluted in $\mathrm{CH}_{3} \mathrm{CN}$ are reported in Figure 5. Several ion peaks are observed at $m / z=1080.7,861.5$ and 799.5 and are assigned to $\left[\mathrm{Pu}(\mathrm{TIPIP})_{3}\right]^{+},\left[\mathrm{Pu}(\mathrm{TIPIP})_{2}\left(\mathrm{NO}_{3}\right)\right]^{+}$and $\left[\mathrm{Pu}(\mathrm{III})(\mathrm{TIPIP})_{2}\right]^{+}$. The $\left[\mathrm{Pu}(\mathrm{TIPIP})_{3}\right]^{+}$species is stable when increasing the skimmer voltage whereas the abundance of $\left[\mathrm{Pu}(\mathrm{TIPIP})_{2}\left(\mathrm{NO}_{3}\right)\right]^{+}$increases at intermediary voltage (about 50V) and then decreases simultaneously with the appearance of $\left[\mathrm{Pu}^{(\mathrm{III})}(\mathrm{TIPIP})_{2}\right]^{+}$. This is consistent with the fragmentation studies showing the formation of $\left[\mathrm{Pu}^{(\mathrm{III})}(\mathrm{TIPIP})_{2}\right]^{+}$by collision induced dissociation of $\left[\mathrm{Pu}(\mathrm{TIPIP})_{3}\right]^{+}$and $\left[\mathrm{Pu}(\mathrm{TIPIP})_{2}\left(\mathrm{NO}_{3}\right)\right]^{+}$. An ion of low abundance at $\mathrm{m} / \mathrm{z}=924.5$ assigned to $\left[\mathrm{Pu}(\mathrm{TIPIP})(\mathrm{HTIPIP})\left(\mathrm{NO}_{3}\right)_{2}\right]^{+}$is also observed. A comparison of the MS data collected for Pu-TPIP- (1) and Pu-TIPIP- (2) shows ions with two ligands and one or two 
nitrate groups for the Pu-TIPIP complexes only (Figure S9 of the SI). This suggests an average lower Pu:ligand stoichiometry for $\mathbf{2}$ than for $\mathbf{1}$. A previous study on $\mathrm{Ce}(\mathrm{IV})$, considered as an analogue of $\mathrm{Pu}(\mathrm{IV})\left(\mathrm{R}_{\mathrm{Ce}(\mathrm{IV})}=0.97 \AA \text { and } \mathrm{R}_{\mathrm{Pu}(\mathrm{IV})}=0.96 \AA\right)^{40}$, reported the formation of $\left[\mathrm{Ce}(\mathrm{TIPIP})_{2}\left(\mathrm{NO}_{3}\right)_{2}\right]$ by the reaction of $\left[\mathrm{NH}_{4}\right]_{2}\left[\mathrm{Ce}\left(\mathrm{NO}_{3}\right)_{6}\right]$ with KTIPIP in $\mathrm{MeCN}$. With a quite similar synthesis for plutonium, and the presence of observed ions by ESI compatible with the $\mathrm{Pu}(\mathrm{TIPIP})_{2}\left(\mathrm{NO}_{3}\right)_{2}$ species, one hypothesis is that this particular complex, $\mathrm{Pu}$ (TIPIP $)_{2}\left(\mathrm{NO}_{3}\right)_{2}$, is part of the species in solution. The loss of nitrates from this compound during ionization in the gas phase could result in the formation of a $\left[\mathrm{Pu}(\mathrm{TIPIP})_{2}\left(\mathrm{NO}_{3}\right)\right]^{+}$ species. The second nitrate ion could also be easily released resulting in a decrease of the coordination number of the actinide. The metal becomes insufficiently coordinated and can attach to a TIPIP- ion to give $\left[\mathrm{Pu}(\mathrm{TIPIP})_{3}\right]^{+}$. However, the presence of this ion could also be explained by the ionization of the $\mathrm{Pu}(\mathrm{TIPIP})_{3}\left(\mathrm{NO}_{3}\right)$ complex as for compound 1 ([Pu(TPIP $\left.\left.)_{3}\left(\mathrm{NO}_{3}\right)\right]\right)$.

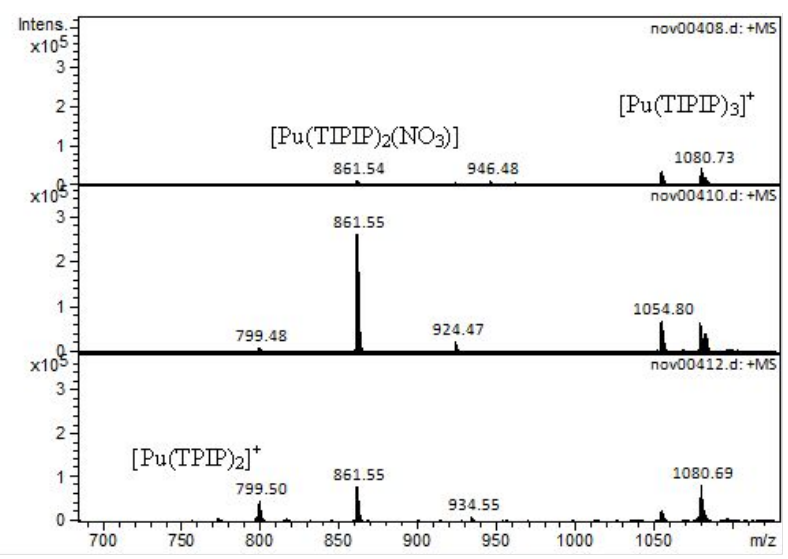

Figure 5 - ESI-MS spectra $\mathrm{m} / \mathrm{z}$ range $700-1550$ of 2 diluted in ethanol and 1/1000th in $\mathrm{CH}_{3} \mathrm{CN}$. Skimmer voltage $30 \mathrm{~V}(\mathrm{~A}), 50 \mathrm{~V}(\mathrm{~B})$ and $70 \mathrm{~V}(\mathrm{C})$.

Since (i) two complexes are observed by NMR spectroscopy, (ii) the presence of coordinated nitrate is confirmed by vibrational spectroscopy and (iii) the interpretation of the ESI spectra, there are likely two possibilities: (a) coexistence of two complexes in the solid state and solution, $\mathrm{Pu}(\mathrm{TIPIP})_{3}\left(\mathrm{NO}_{3}\right)$ and $\mathrm{Pu}$ (TIPIP $)_{2}\left(\mathrm{NO}_{3}\right)_{2}$, or (b) the presence of only $\mathrm{Pu}(\mathrm{TIPIP})_{2}\left(\mathrm{NO}_{3}\right)_{2}$ with non-magnetically equivalent $\mathrm{P}$ atoms in a 2:1 ratio. Considering the literature with $\mathrm{Ce}(\mathrm{IV})$ that forms $\mathrm{Ce}(\mathrm{TIPIP})_{2}\left(\mathrm{NO}_{3}\right)_{2}$ and the ESI MS 
of compound 1 ([Pu(TPIP) $\left.\left.)_{3}\left(\mathrm{NO}_{3}\right)\right]\right)$ presenting peaks corresponding to $\mathrm{Pu}(\mathrm{TPIP})_{3}{ }^{+}$only and not $\mathrm{Pu}(\mathrm{TPIP})_{2}\left(\mathrm{NO}_{3}\right)_{2}$ and assuming that the ionization strength of the two $\mathbf{1}$ and $\mathbf{2}$ compounds are equivalent, we believe that we have a mix of the two complexes $\mathrm{Pu}(\mathrm{TIPIP})_{3}\left(\mathrm{NO}_{3}\right)$ and $\mathrm{Pu}(\mathrm{TIPIP})_{2}\left(\mathrm{NO}_{3}\right)_{2}$. The corresponding UV-vis spectrum of $\mathbf{2}$ confirming that plutonium exists in the +IV oxidation state in ethanol solutions of $\mathbf{2}$ is given Figure S8 of the SI.

\section{Compound 3: $\left[\mathrm{PuO}_{2}\right.$ (TPIP)(HTPIP) $\left.\left(\mathrm{NO}_{3}\right)\right]$}

The molecular structure of $\mathbf{3}$ is formulated as $\left[\mathrm{PuO}_{2}(\mathrm{TPIP})(\mathrm{HTPIP})\left(\mathrm{NO}_{3}\right)\right]$ by single crystal X-ray diffraction analysis (Figure 6). The main interatomic distances are gathered in Table S4 of the SI. The $\mathrm{Pu}=\mathrm{O}$ bond length of $1.736(2) \AA$ is in agreement with the average $\mathrm{Pu}(\mathrm{VI})=\mathrm{O}$ distance of $1.739 \AA$ determined by the analysis of $28 \mathrm{Pu}(\mathrm{VI})$ structures $(\mathrm{CN}=5$ and 6) reported in the Cambridge Crystallographic Database. The structure comprises a near linear plutonyl moiety $\left(178.0(1)^{\circ}\right)$ with equatorial coordination by one bidentate TPIP-, one monodentate HTPIP and one bidentate nitrate. The protonation is evident in the longer P-N bond lengths in HTPIP (1.635(2), 1.665(2) $\AA$ ) compared to TPIP(1.585(3), 1.581(3) $\AA$ ). The $\mathrm{P}=\mathrm{O}$ bond lengths also provide evidence of protonation with TPIP- ligand $\mathrm{P}=\mathrm{O}_{\text {TPIP }}$ bond lengths of $1.522(2)$ and 1.523(2) $\AA$ vs. 1.499(2) $\AA$ for the coordinated $\mathrm{P}=\mathrm{O}_{\mathrm{HTPIP}}$ and 1.493(3) $\AA$ for the uncoordinated $\mathrm{P}=\mathrm{O}_{\text {HTPIP. }}$ The shortened $\mathrm{P}=\mathrm{O}$ distances with protonation is related to less electronic delocalization from the nitrogen atom towards the phosphorus group. In addition, this imido proton forms a hydrogen bond with the uncoordinated phosphine oxygen on an adjacent monomer $(\mathrm{d}=1.80(2) \AA$ ), which may help to influence the crystal packing (Figure 7). With a value of $2.476 \AA$ and a coordination number of 5, the average $\mathrm{Pu}-\mathrm{O}_{\text {nitrate }}$ distance is in agreement with the four $\mathrm{Pu}(\mathrm{VI})$ structures in the Cambridge Crystallographic Database containing bidentate nitrates with a Pu-O bond distance in the range 2.472 and 2.525 for a coordination number of 6 . 


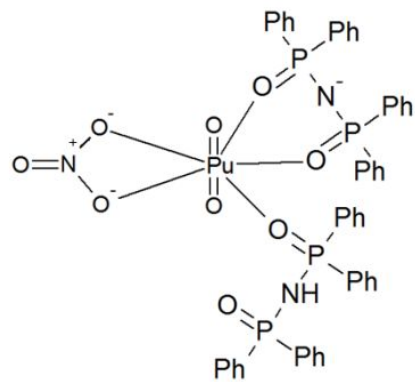

Figure $6-3 \mathrm{D}$ and $2 \mathrm{D}$ views of the structure of $3 . \mathrm{H}$ atoms are omitted for clarity. Ellipsoids are drawn at the $40 \%$ probability level.

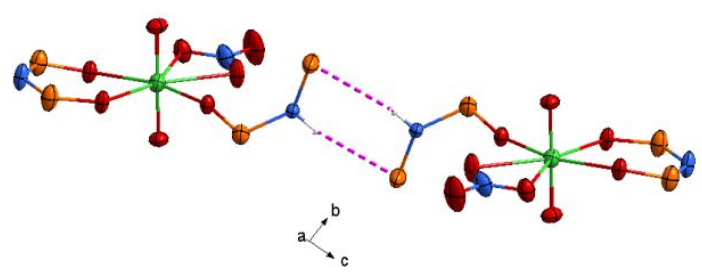

Figure 7 - Hydrogen bonding between the imido proton and the phosphine oxide moiety in $\mathbf{3}$. Phenyl groups have been omitted for clarity.

Attempts to crystallize oligomers (as seen in uranyl and neptunyl chemistry ${ }^{20,21}$ ) by changing crystallization solvents and conditions were unsuccessful, as well as attempts to displace coordinated nitrate with $\mathrm{Ph}_{3} \mathrm{PO}$ or a coordinating solvent. Interestingly, recollection of the data after one week showed no degradation in crystal quality, indicating that the complex itself is stable in the solid state. 


\begin{abstract}
Nevertheless, with an alpha radiolysis far more important for plutonium than neptunium, the crystals are likely less stable in the case of plutonium.
\end{abstract}

The ESI-MS spectra in positive ionization mode of 3 dissolved in $\mathrm{CH}_{2} \mathrm{Cl}_{2}$ and diluted $1 / 1000^{\text {th }}$ in $\mathrm{CH}_{3} \mathrm{CN}$ are reported in SI (Figure S13). Two main ion peaks are observed at m/z=1488.4 and 1104.4 assigned to $\left[\mathrm{Pu}^{(\mathrm{IV})}(\mathrm{TPIP})_{3}\right]^{+}$and $\left[\mathrm{PuO}_{2} \text { (TPIP)(HTPIP) }\right]^{+}$. Experiments performed in negative ionization mode show only the presence of the plutonyl ion. Consequently, it is likely that plutonium(VI) is reduced to plutonium(IV) during the transfer in the gas phase. This change of oxidation state has already been observed for collision induced dissociation of plutonyl -ligand complexes ${ }^{55,67} \cdot\left[\mathrm{Pu}^{(\mathrm{IV})}(\mathrm{TPIP})_{3}\right]^{+}$is not considered as representative of species in solution but would be an artefact due to the transfer of species in the gas phase. Moreover, fragmentation spectra of the $\left[\mathrm{PuO}_{2}(\mathrm{TPIP})(\mathrm{HTPIP})\right]^{+}$ion indicates that the TPIP- ligands are strongly bound to the plutonyl cation in the gas phase as no peaks corresponding to loss of ligand were observed. From these data, it seems that the presence of only $\left[\mathrm{PuO}_{2}(\mathrm{TPIP})(\mathrm{HTPIP})\right]^{+}$ions is consistent with the complex initially introduced in the solution and is in agreement with the crystal structure in which plutonyl is coordinated to one bidentate TPIP-, one protonated HTPIP and one nitrate anion. During the ionization step and transfer of ions into the gas phase, the metal-nitrate interactions are weakened, facilitating the loss of the nitrate group and leading to the formation of the $\left[\mathrm{PuO}_{2}(\mathrm{TPIP})(\mathrm{HTPIP})\right]^{+}$ion.

Multinuclear NMR spectroscopic studies of 3 (see SI, Figure S12) after dissolution in $\mathrm{CDCl}_{3}$ were hindered by the paramagnetic nature of the $\mathrm{Pu}(\mathrm{VI})$ ion ${ }^{81}$ and fast chemical exchanges of TPIP- with different coordination sites around the actinyl unit, leading to very broad peaks in the ${ }^{1} \mathrm{H}$ NMR spectrum at room temperature. At $-15^{\circ} \mathrm{C}$, the ${ }^{1} \mathrm{H}\left\{{ }^{13} \mathrm{C}\right\}$ spectrum presents sharper resonances and at least 7 peaks between -5 and $-20 \mathrm{ppm}$ are observed. It seems that a chemical exchange between cis and trans isomers occurs in chloroform solution as previously observed with phosphinimine or phosphine oxide 82,83 ligands. 
The Raman spectra of $\mathbf{3}$ presented in Table S5 and Figures S14 and S22 is nearly identical to that recorded for 1 ([Pu(TPIP) $\left.\left.)_{3}\left(\mathrm{NO}_{3}\right)\right]\right)$, except for the presence of a strong band at $802 \mathrm{~cm}^{-1}$ that corresponds to the symmetric stretch of the plutonyl moiety. The bands assigned to the phenyl groups as well as the nitrate groups can be recognized in addition to some shifts that are likely due to various phenyl orientations and potential interactions between phenyls of several monomers (pi-interactions). With one bidentate non-protonated ligand and one monodentate protonated molecule in the coordination sphere, several $\mathrm{P}=\mathrm{O}$ bands are observed. Considering the previously described $\mathrm{P}=\mathrm{O}$ frequencies according to the different protonation states of the ligand and the known decrease of the $\mathrm{P}=\mathrm{O}$ energy with complexation, it is possible to give assignment hypotheses for the $\mathrm{P}=\mathrm{O}$ vibrations for the different configurations: bands at 1068, 1090 and $1190 \mathrm{~cm}^{-1}$ for deprotonated-coordinated TPIP-, the protonated-coordinated phosphonate group and protonated-non-coordinated $\mathrm{P}=\mathrm{O}$ bonds respectively.

The IR spectra of $\mathbf{1}\left(\left[\mathrm{Pu}(\mathrm{TPIP})_{3}\left(\mathrm{NO}_{3}\right)\right]\right)$ and $\mathbf{3}$ (Figure $\mathrm{S} 14$ of the supporting information) are very similar with the exception of bands at 922 and $1519 \mathrm{~cm}^{-1}$ in the spectrum of $\mathbf{3}$. The first one is attributed to the asymmetric stretch $\left(v_{3}\right)$ of the plutonyl moiety whereas we were unable to confidently assign the remaining band.

The different analyses are in agreement and demonstrate the conservation and stabilization of $\mathrm{Pu}(\mathrm{VI})$ in the $\left[\mathrm{PuO}_{2}\right.$ (TPIP)(HTPIP) $\left.\left(\mathrm{NO}_{3}\right)\right]$ complex in solution. The UV-vis spectrum of 3 is given in Figure S11 of the supporting information, and again confirms the identity of the oxidation state of the plutonium cation as + VI.

\section{Compound 4: $\left[\mathrm{PuO}_{2}(\mathrm{HTIPIP})_{2}\left(\mathrm{H}_{2} \mathrm{O}\right)\right]\left[\mathrm{NO}_{3}\right]_{2}$}

The structure of 4 was determined as $\left[\mathrm{PuO}_{2}(\mathrm{HTIPIP})_{2}\left(\mathrm{H}_{2} \mathrm{O}\right)\right]\left[\mathrm{NO}_{3}\right]_{2}$ by single crystal XRD (Figure 8). The structure comprises a linear plutonyl moiety with equatorial coordination by two bidentate HTIPIP ligands and one $\mathrm{H}_{2} \mathrm{O}$ molecule to give a pentagonal bipyramidal coordination geometry. Two 
non-coordinating nitrate anions provide charge balance. $\mathrm{The} \mathrm{Pu}=\mathrm{O}_{y l}$ bond lengths are statistically identical at $1.737(2)$ and $1.744(2) \AA$, and in the range of those observed in the literature $(1.739 \AA$ - values determined considering all the plutonyl(VI) structures reported in the Cambridge Crystallographic Database). At $179.7^{\circ}$, the $\mathrm{O}=\mathrm{Pu}=\mathrm{O}$ angle is close to the expected linearity and the average $\mathrm{Pu}-\mathrm{O}_{\mathrm{HTIPIP}}$ bond length of $2.361 \AA$ is comparable with the reported U-O $\mathrm{O}_{\text {TPIP }}$ bond lengths in the related complex $\left[\mathrm{UO}_{2}(\mathrm{TPIP})_{2}\right](2.35 \AA) .{ }^{20}$ The Pu-O $\mathrm{H}_{2 \mathrm{O}}$ distance $(2.418(2) \AA)$ matches with the only plutonyl(VI) structure reported with an equatorial coordination number of 5 that presents a $\mathrm{Pu}(\mathrm{VI})-\mathrm{H}_{2} \mathrm{O}$ distance of $2.409 \AA^{84}$, confirming that it is coordinated $\mathrm{H}_{2} \mathrm{O}$ rather than $\mathrm{OH}^{-}$. The longer P-N bond distances of $1.67 \AA$ in 4 vs. $1.58 \AA$ for the unprotonated ligand in $\mathbf{1}\left(\left[\mathrm{Pu}(\mathrm{TPIP})_{3}\left(\mathrm{NO}_{3}\right)\right]\right)$ confirms the ligand protonation. To the best of our knowledge, there is no previously reported example of bidentate coordination of a protonated imidodiphosphinate ligand to a lanthanide or actinide and only a limited number of reported transition metal complexes. ${ }^{85,86,87}$

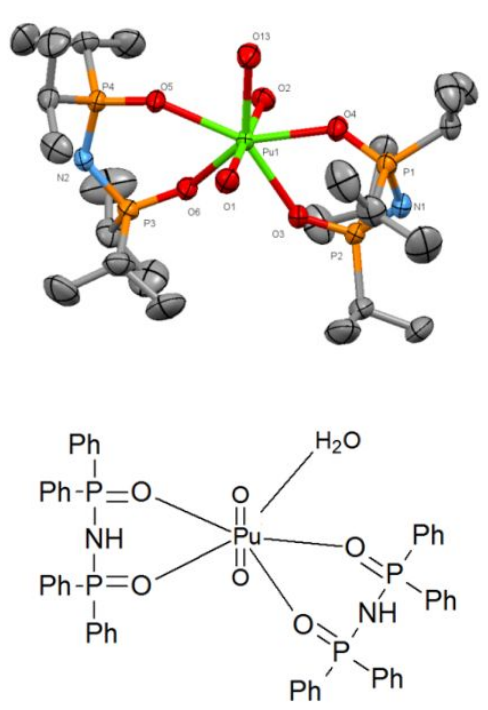

Figure $8-3 \mathrm{D}$ and $2 \mathrm{D}$ views of $\left[\mathrm{PuO}_{2}(\mathrm{HTIPIP})_{2}\left(\mathrm{H}_{2} \mathrm{O}\right)\right]^{2+}$ in $4 . \mathrm{H}$ atoms are omitted for clarity. Ellipsoids are drawn at the $40 \%$ probability level. 
Conversely to 3 ([PuO 2 (TPIP)(HTPIP) $\left.\left.\left(\mathrm{NO}_{3}\right)\right]\right)$, the NMR spectra of 4 dissolved in $\mathrm{CDCl}_{3}$ at room temperature (see supporting information, Figure S16) gives only two broad signals (at -42 and -30 ppm) that can be assigned to cis/trans isomers in the ${ }^{31} \mathrm{P}$ spectrum. From deconvolution analysis, the integration ratio is approximately 1:6 respectively. This ratio is also found with the broad ${ }^{1} \mathrm{H}$ signals centered at -3 and -10 ppm and can be assigned to the $\mathrm{CH}$ and $\mathrm{CH}_{3}$ protons belonging to both isomers (cis and trans) respectively.

The ESI-MS spectra in positive ionization mode of 4 dissolved in ethanol and diluted in $1 / 1000^{\text {th }}$ in $\mathrm{CH}_{3} \mathrm{CN}$ are reported in the SI (Figure S17). Several ion peaks are observed at $\mathrm{m} / \mathrm{z}=416.5,552.2$, 832.5, 895.5 and 1079.6 assigned to $\left[\mathrm{PuO}_{2}\left(\mathrm{HTIPIP}_{2}\right]^{2+},\left[\mathrm{PuO}_{2}(\mathrm{HTIPIP}]^{+},\left[\mathrm{PuO}_{2}(\mathrm{TIPIP})(\mathrm{HTIPIP})\right]^{+}\right.\right.$, $\left[\mathrm{PuO}_{2}(\mathrm{HTIPIP})_{2}\left(\mathrm{NO}_{3}\right)\right]^{+}$and $\left[\mathrm{Pu}(\mathrm{IV})(\mathrm{TIPIP})_{3}\right]^{+}$respectively. As previously discussed, $\left[\mathrm{Pu}^{(\mathrm{IV})}(\mathrm{TIPIP})_{3}\right]^{+}$is not considered as representative of the species in solution. The fragmentation spectra of $\mathrm{Pu}(\mathrm{VI})$ species show the fragmentation of the ligand without decomplexation, indicating that the ligand is strongly bound to the metal. The ions observed at low skimmer voltage $\left[\mathrm{PuO}_{2}(\mathrm{HTIPIP})_{2}\right]^{2+},\left[\mathrm{PuO}_{2}(\mathrm{TIPIP})(\mathrm{HTIPIP})\right]^{+}$and $\left[\mathrm{PuO}_{2}(\mathrm{HTIPIP})_{2}\left(\mathrm{NO}_{3}\right)\right]^{+}$are consistent with the structure of the crystal. After dissolution of $\mathbf{4}$, ionization and transfer in the gas phase, the expected cation should be $\left[\mathrm{PuO}_{2}(\mathrm{HTIPIP})_{2}\left(\mathrm{H}_{2} \mathrm{O}\right)\right]^{2+}$ since the nitrate ions reside in the external coordination sphere. In the gas phase, the water molecule in the metal coordination sphere can be easily released, leading to $\left[\mathrm{PuO}_{2}(\mathrm{HTIPIP})_{2}\right]^{2+}$. After dehydration, the metal becomes insufficiently coordinated. Two ways are possible to complete the coordination sphere of the metal: a nitrate can coordinate the metal leading to $\left[\mathrm{PuO}_{2}(\mathrm{HTIPIP})_{2}\left(\mathrm{NO}_{3}\right)\right]^{+}$or a nitrogen atom can coordinate to the metal after release of a proton leading to $\left[\mathrm{PuO}_{2} \text { (TIPIP)(HTIPIP) }\right]^{+}$. The ion $\left[\mathrm{PuO}_{2}(\mathrm{HTIPIP})\right]^{+}$is only observed at high skimmer voltage (from 50V) suggesting that it could be formed during the ionization process. The NMR and ESI-MS data are consistent with the presence of cis and trans isomers and agree with the crystal structure. Multinuclear NMR spectroscopy further demonstrates the presence of two complexes in solution. 
The Raman spectrum of 4, presented in Figures S18 and S22 of the supporting information, is quite similar to that of compound 2 (mixture of $\mathrm{Pu}(\mathrm{TIPIP})_{3}\left(\mathrm{NO}_{3}\right)$ and $\left.\mathrm{Pu}(\mathrm{TIPIP})_{2}\left(\mathrm{NO}_{3}\right)_{2}\right)$, with the main band of the isopropyl groups observed at the same frequencies as described for $\mathbf{2}$. The main additional contribution compared to 2 is at $806 \mathrm{~cm}^{-1}$ (see Table $\mathrm{S} 7$ of the SI) and is assigned to the $\mathrm{O}=\mathrm{Pu}=\mathrm{O}$ total symmetric stretch. The $\mathrm{P}=\mathrm{O}$ bond is likely to appear within the same range as the nitrate vibrations and asymmetric C-C-C stretch, between 1030 and $1050 \mathrm{~cm}^{-1}$. To complete the vibrational analysis, an IR spectrum was also recorded (see SI, Figure S18). The asymmetric stretch of the plutonyl group can be identified at $922 \mathrm{~cm}^{-1}$ in the IR spectrum of $\mathbf{4}$, as well as nitrate ion bond stretches with intense bands around $1400 \mathrm{~cm}^{-1}$. Both techniques confirm the presence of nitrate groups.

Together, these data lead to the conclusion that this compound in the +VI oxidation state is stable with respect to ligand redistribution and redox reactions in both the solid and liquid phase. The UV-vis spectrum of 4 in $\mathrm{CH}_{2} \mathrm{Cl}_{2}$ solution presented in Figure $\mathrm{S} 15$ of the supporting information confirms the oxidation state assignment in solution equal to that determined by single crystal XRD in the solid state.

Compound 5: [( $\left.\left.\mathrm{UO}_{2} / \mathrm{PuO}_{2}\right)(\mathrm{TPIP})(\mathrm{HTPIP})\left(\mathrm{NO}_{3}\right)\right]$

In an attempt to synthesize a mixed uranyl-plutonyl complex, possibly connected by a bridging TPIP- ligand as previously reported for uranyl(VI), a mixed solid containing both uranyl(VI) and plutonyl(VI) ions was formed by adding one equivalent of solid uranyl(VI) nitrate into a plutonyl(VI) nitrate solution before the addition of NaTPIP (5). The UV-vis data of a large amount of resultant crystals dissolved in $\mathrm{CH}_{2} \mathrm{Cl}_{2}$ showed the presence of both $\mathrm{U}(\mathrm{VI})$ and $\mathrm{Pu}(\mathrm{VI})$ (Figure 9), with a shift due to complexation compared to $\mathrm{U}(\mathrm{VI})$ and $\mathrm{Pu}(\mathrm{VI})$ in $1 \mathrm{M}$ nitric acid solution, confirming the presence of both complexed metals in the bulk crystals. 
2

3

4

5

6

7

8

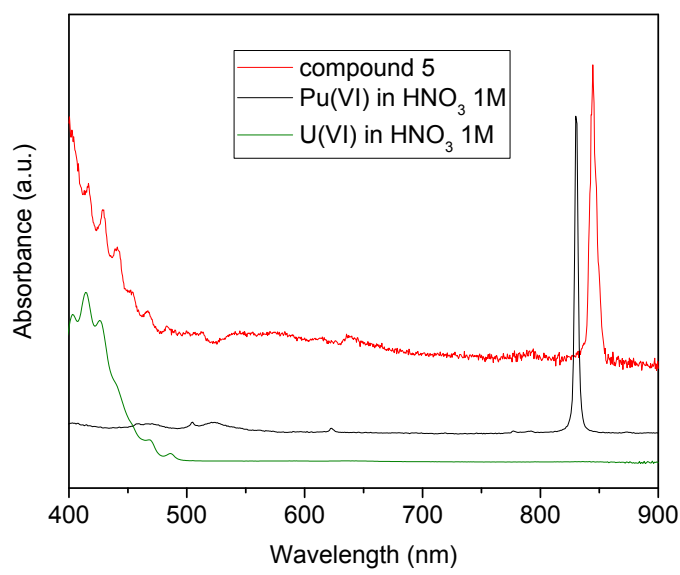

Figure 9 -UV-vis spectrum of 5 dissolved in $\mathrm{CH}_{2} \mathrm{Cl}_{2}$ clearly showing the fingerprint uranyl(VI) LMCT absorption at ca. $420 \mathrm{~nm}$ and the characteristic plutonyl intra f-f absorption at ca. $850 \mathrm{~nm}$.

The ESI-MS spectra in positive ionization mode of 5 dissolved in $\mathrm{CH}_{2} \mathrm{Cl}_{2}$ and in $1 / 1000^{\text {th }}$ in $\mathrm{CH}_{3} \mathrm{CN}$ are reported Figure 10 and Figure S20 of the SI. Several ion peaks are observed at $\mathrm{m} / z=1103.4$ and 1487.4. The ion observed at $m / z=1487.4$ is assigned to $\left[\mathrm{Pu}^{(\mathrm{IV})}(\mathrm{TPIP})_{3}\right]^{+}$as previously observed and is not considered as representative of the species in solution. The following discussion focuses only on ions for which the oxidation state of the actinyl cation does not change. For the ion observed at $\mathrm{m} / z=1103.4$, comparison of the experimental and simulated isotopic patterns (calculated from $\left[\mathrm{UO}_{2}(\mathrm{TPIP})(\mathrm{HTPIP})\right]^{+}$or $\left[\mathrm{PuO}_{2} \text { (TPIP)(HTPIP) }\right]^{+}$see Figure 10) indicate that only considering uranyl or plutonyl species, the calculated isotopic patterns do not fully match the experimental data. The experimental pattern is more closely matches that of $\left[\mathrm{UO}_{2}(\mathrm{TPIP})(\mathrm{HTPIP})\right]^{+}$including a small ratio of $\left[\mathrm{PuO}_{2}(\mathrm{TPIP})(\mathrm{HTPIP})\right]^{+}$(Figure 10). This result confirms a mixture of two $\mathrm{U}(\mathrm{VI})$ and $\mathrm{Pu}(\mathrm{VI})$ complexes is present in the solution.

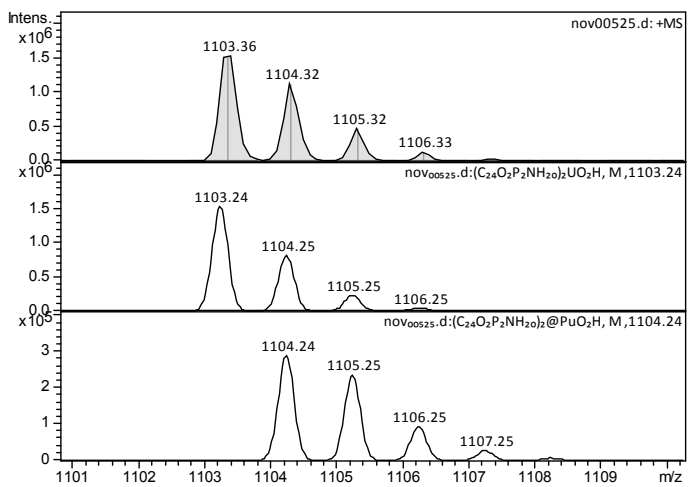


Figure 10 -ESI positive mass spectrum of 5 (top), showing the experimental isotopic pattern at $\mathrm{m} / \mathrm{z}=$ 1103.6 (top) and the predicted isotope patterns for $\left[\mathrm{UO}_{2} \text { (TPIP)(HTPIP) }\right]^{+}$(middle) and $\left[\mathrm{PuO}_{2} \text { (TPIP)(HTPIP) }\right]^{+}$(bottom).

Raman spectroscopy performed on one single-crystal (see Figure S21 and Table S9 of the SI) shows that $\mathbf{5}$ exhibits the same Raman spectrum as $\mathbf{3}\left(\left[\mathrm{PuO}_{2}(\mathrm{TPIP})(\mathrm{HTPIP})\left(\mathrm{NO}_{3}\right)\right]\right)$ in addition to the presence of a new peak at $844 \mathrm{~cm}^{-1}$ that corresponds to previously reported uranyl(VI)-TPIP complexes with a range between 827 and $840 \mathrm{~cm}^{-1} \cdot{ }^{20,21}$ The main differences result in some small shifts probably indicating a modification of the complexation strength due to the presence of U(VI) within the same site as $\mathrm{Pu}(\mathrm{VI})$. Indeed, the bands at 1068 and $1091 \mathrm{~cm}^{-1}$ in 3, attributed to the $\mathrm{P}=\mathrm{O}$ stretch of the deprotonated and protonated complexed ligands respectively, shift to 1063 and $1085 \mathrm{~cm}^{-1}$ in $\mathbf{5}$. Together, the presence of the two distinct "yl" Raman bands, the quasi perfect similitude between the spectra of $\mathbf{3}$ and $\mathbf{5}$ (no supplementary doubling or shoulder) and the shift of only specific bands indicate that the studied crystal contains a mixture of co-crystallized uranium and plutonium complexes. The IR spectrum (see SI, Figure $\mathrm{S} 21$ ) of $\mathbf{5}$ is identical to the one of $\mathbf{3}$ containing only $\mathrm{Pu}(\mathrm{VI})$. According to a previous study ${ }^{20}$, the asymmetric $\mathrm{O}=\mathrm{U}=\mathrm{O}$ vibration of this family of compounds appears between 910 and $920 \mathrm{~cm}^{-1}$, at the same frequency as the plutonyl one. Therefore, the two bands are likely superimposed. The small shoulder observed on the left side of the band for compound $\mathbf{5}$ is additional evidence confirming the presence of both cations within the single crystal.

Single crystal XRD of $\mathbf{5}$ showed that it has the same unit cell as $\mathbf{3}$ with nearly identical lattice parameters and the structure was solved as $\left[\mathrm{AnO}_{2}(\mathrm{TPIP})(\mathrm{HTPIP})\left(\mathrm{NO}_{3}\right)\right]$. The lattice parameters should be longer than the $\mathrm{Pu}$ ones but the ionic radii difference between $\mathrm{U}(\mathrm{VI})$ and $\mathrm{Pu}(\mathrm{VI}), 0.71$ and $0.73 \AA$ (coordination number $=8$ ), is not substantial meaning that this is the likely reason why the difference of unit cell parameters between $\mathbf{3}$ and $\mathbf{5}$ is small. Upon inspection by eye and through the microscope, the single crystals $\mathbf{3}$ and $\mathbf{5}$ show uniform crystal morphology and interestingly showed a significant change in 
color from the isomorphous individual single component metal complex of 3. Crystallized samples of $\mathbf{5}$ were yellow in color, whereas those of $\mathbf{3}$ were orange-brown in color, indicating that crystals of $\mathbf{5}$ were not a $\mathrm{Pu}(\mathrm{VI})$ single metal complex and probably contain a large amount of uranyl(VI) (Figure 11). Based upon the additional spectroscopic characterization (UV-vis, mass spectroscopy and Raman spectroscopy), the crystals are verified to contain a mixture of co-crystallized $\left[\mathrm{PuO}_{2}(\mathrm{TPIP})(\mathrm{HTPIP})\left(\mathrm{NO}_{3}\right)\right]$ and $\left[\mathrm{UO}_{2}\right.$ (TPIP)(HTPIP) $\left.\left(\mathrm{NO}_{3}\right)\right]$ randomly distributed in crystallographically identical sites. Due to the very similar electron densities of the two metals, it was not possible to assign the occupancies of the metal sites crystallographically. The percentage of each cation was approximately determined by examining at the UV-vis data after dissolution of crystals in $\mathrm{CH}_{2} \mathrm{Cl}_{2}$ and considering the same order of magnitude for the molar attenuation coefficient between the $\mathrm{U}(\mathrm{VI})$ and the $\mathrm{Pu}(\mathrm{VI})$ complexes as the extinction coefficient between the free cations in nitric acid solution ${ }^{88}$. Compound $\mathbf{5}$ was thus crystallographically refined with fixed $90 \% \mathrm{U}$ and $10 \% \mathrm{Pu}$ occupancy. These percentages are quite in agreement with the color of the crystals more yellow than brown. In 5, $\mathrm{U}$ and $\mathrm{Pu}$ are constrained to occupy the same site so differences between their bond lengths cannot be discussed. The $\mathrm{An}=\mathrm{O}_{y l}$ bond lengths are 1.748(2) and 1.756(3) $\AA$, which are slightly longer than the bond lengths in 3 (1.733(3) and 1.736(2) $\AA$ ) where the structure is $100 \% \mathrm{Pu}(\mathrm{VI})$ but shorter than those reported for $\left[\mathrm{UO}_{2}(\mathrm{TPIP})_{2}\right]$ with $\mathrm{U}=\mathrm{O}_{y l}$ bond lengths of $1.777(1)$ and 1.783(1) A.. ${ }^{20}$ In addition, the An-O ${ }_{\text {TPIP }}$ bond lengths are slightly smaller for $\mathbf{3}$ than $\mathbf{5}$ with 2.315 and 2.318 $\AA$ respectively. The difference is more important for the nitrate ion with an average of $2.489 \AA$ for the mixed compound and $2.476 \AA$ for the plutonyl one. 


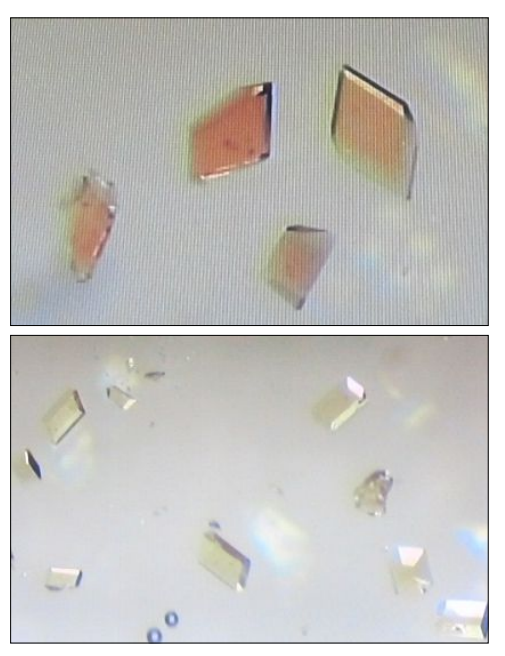

Figure 11 - Crystals of $\mathbf{3}$ (top) and 5 (bottom), showing a clear difference in color due to the presence of uranium.

From ${ }^{1} \mathrm{H}$ NMR spectroscopic analysis collected after dissolution of the crystals in THF, a broad peak observed at $-10 \mathrm{ppm}$ indicates the presence of a paramagnetic $\mathrm{Pu}(\mathrm{VI})$-TPIP complex. More interestingly, the 2D NMR experiment CIGAR ${ }^{31} \mathrm{P}-{ }^{1} \mathrm{H}$ exhibits two sets of cross peaks (see Figure $\mathrm{S} 19$ of the SI): one belonging to a $\mathrm{Pu}(\mathrm{IV})$-TPIP complex (-51 ppm on the ${ }^{31} \mathrm{P}$ NMR scale) and a second one certainly belonging to a U(VI)-TPIP complex (23 ppm). The Pu(IV) was probably initially present in the actinide solution prior addition of the TPIP- ligand (from reduction of the $\mathrm{Pu}(\mathrm{VI})$ starting solution in nitric acid). Indeed, two proton signals, in the 6 to $8 \mathrm{ppm}$ area and in a 3:2 ratio, can be assigned to U(VI)-TPIP rather than the uncoordinated TPIP- ligand because of their low resolution and a small shift from 13.4 ppm which is due to the diamagnetic behavior of the uranyl(VI) ion. Regarding the Pu(IV)-TPIP complex, it appears that the amount of such compound in THF solution is quite low because the ${ }^{31} \mathrm{P}$ signal can only be seen on the indirect detection 2D NMR experiment (CIGAR) which is more sensitive than a ${ }^{31} \mathrm{P}$ direct detection experiment. The $\mathrm{Pu}(\mathrm{VI})$ complex is too paramagnetic to be observed under the conditions of the experiment (see compound $\mathbf{3}$ ). 


\section{Discussion}

In all cases, the imidophosphinate ligands are able to stabilize plutonium in both the $+\mathrm{IV}$ and $+\mathrm{VI}$ oxidation states and interestingly do not induce any internal redox chemistry contrary to that observed for neptunium with an oxidation of $\mathrm{Np}(\mathrm{V})$ to $\mathrm{Np}(\mathrm{VI})$ upon complexation in 50:50 v:v $\mathrm{MeOH} / \mathrm{CH}_{2} \mathrm{Cl}_{2}{ }^{21}$. Moreover, no reduction of $\mathrm{Pu}(\mathrm{VI})$ in protic solvents was observed which may be expected to occur by analogy with $\mathrm{Np}(\mathrm{VI})$ chemistry.

The nature of the R-group ( $\mathrm{R}=$ phenyl or ${ }^{i} \mathrm{Pr}$ ) has a large impact on the complexation of $\mathrm{An}(\mathrm{VI})$ and An(IV) cation. It seems that there is less ligand in the coordination sphere of the actinide for the TIPIP- complexes than the TPIP- ones for the Pu(IV) metallic center. DFT calculations were performed to help rationalize the influence of the $\mathrm{R}$ group attached to the $\mathrm{P}$ atoms on plutonium structures. Geometries of $\mathrm{Pu}(\mathrm{IV})$ with one to four TPIP- and TIPIP- ligands were optimized; $\mathrm{PuL}\left(\mathrm{NO}_{3}\right)_{3} \mathrm{PuL}_{2}\left(\mathrm{NO}_{3}\right)_{2}, \mathrm{PuL}_{3}\left(\mathrm{NO}_{3}\right)$ and $\mathrm{PuL}_{4}$ complexes with $\mathrm{L}=$ TPIP- or TIPIP-. The successive ligand binding energies to $\mathrm{Pu}(\mathrm{IV})$ with TPIP and TIPIP were evaluated by considering the following model reactions :

$\mathrm{Pu}\left(\mathrm{NO}_{3}\right)_{3}{ }^{+}+\mathrm{L}^{-} \rightarrow \mathrm{Pu}\left(\mathrm{NO}_{3}\right)_{3} \mathrm{~L}$

$\mathrm{Pu}\left(\mathrm{NO}_{3}\right)_{3} \mathrm{~L}+\mathrm{L}^{-} \rightarrow \mathrm{Pu}\left(\mathrm{NO}_{3}\right)_{2} \mathrm{~L}_{2}+\mathrm{NO}_{3}^{-}$

$\mathrm{Pu}\left(\mathrm{NO}_{3}\right)_{2} \mathrm{~L}_{2}+\mathrm{L}^{-} \rightarrow \mathrm{PuNO}_{3} \mathrm{~L}_{3}+\mathrm{NO}_{3}^{-}$

$\mathrm{PuNO}_{3} \mathrm{~L}_{3}+\mathrm{L}^{-} \rightarrow \mathrm{PuL}_{4}+\mathrm{NO}_{3}^{-}$

Calculated energies (given as $\Delta \mathrm{G}$ and $\Delta \mathrm{H}$ variations) are reported in Table 2. For the formation of the less sterically crowded $\mathrm{Pu}\left(\mathrm{NO}_{3}\right)_{3} \mathrm{~L}$ complex, the TIPIP- ligand exhibits a significantly stronger binding interaction than TPIP- (by $\sim 40 \mathrm{~kJ}^{-\mathrm{mol}^{-1}}$ according to free energy and enthalpy variations). This is consistent with the nature of the $\mathrm{R}$ group; ${ }^{i} \mathrm{Pr}$ is known to have an electron-donating inductive effect while phenyl has an electron-withdrawing inductive effect. With the further addition of a second ligand in replacement of one nitrate ion, TIPIP- than TPIP- remains a stronger ligand, but the energy difference between TIPIP- and TPIP- drops to $9 \mathrm{~kJ}^{-} \mathrm{mol}^{-1}$ for $\Delta \mathrm{G}$, and $15 \mathrm{~kJ}^{-\mathrm{mol}^{-1}}$ for $\Delta \mathrm{H}$. Energy differences further 
decrease in the presence of three ligands and the TPIP- complex is favored if we consider enthalpy variations (by a few $\mathrm{kJ}^{\mathrm{mol}}{ }^{-1}$ ), while the difference in $\Delta \mathrm{G}$ values decreases to zero.

Table 2. Calculated energy variations for the successive ligand coordination to $\mathrm{Pu}(\mathrm{IV}), \Delta \mathrm{H}$ and $\Delta \mathrm{G}$ values in $\mathrm{kJ} \cdot \mathrm{mol}^{-1}, \mathrm{~L}=$ TPIP-, TIPIP-

\begin{tabular}{|l|ll|ll|}
\hline & \multicolumn{2}{|c|}{$\Delta \mathrm{G}$} & \multicolumn{2}{c|}{$\Delta \mathrm{H}$} \\
\hline Model reaction & TPIP- $^{-}$ & TIPIP- $^{-}$ & TPIP- $^{-}$ & TIPIP- \\
$\mathrm{Pu}\left(\mathrm{NO}_{3}\right)_{3}{ }^{+}+\mathrm{L}-\rightarrow \mathrm{Pu}\left(\mathrm{NO}_{3}\right)_{3} \mathrm{~L}$ & -208 & -247 & -263 & -303 \\
$\mathrm{Pu}\left(\mathrm{NO}_{3}\right)_{3} \mathrm{~L}+\mathrm{L}^{-} \rightarrow \mathrm{Pu}\left(\mathrm{NO}_{3}\right)_{2} \mathrm{~L}_{2}+\mathrm{NO}_{3}^{-}$ & -116 & -127 & -126 & -141 \\
$\mathrm{Pu}\left(\mathrm{NO}_{3}\right)_{2} \mathrm{~L}_{2}+\mathrm{L}^{-} \rightarrow \mathrm{PuNO}_{3} \mathrm{~L}_{3}+\mathrm{NO}_{3}^{-}$ & -46 & -46 & -72 & -66 \\
$\mathrm{PuNO}_{3} \mathrm{~L}_{3}+\mathrm{L}^{-} \rightarrow \mathrm{PuL}_{4}+\mathrm{NO}_{3}^{-}$ & +55 & - & +18 & - \\
\hline
\end{tabular}

It was not possible to add four bidendate TIPIP- ligands to the $\mathrm{Pu}(\mathrm{IV})$ coordination sphere, geometry optimizations end up with one monodendate ligand because of steric hindrance in the $\mathrm{Pu}(\mathrm{IV})$ inner coordination sphere. Geometry optimization of $\mathrm{Pu}(\mathrm{TPIP})_{4}$ was successful but energy variations become positive and suggested that the formation of $\mathrm{PuL}_{4}$ is less favorable than $\mathrm{PuL}_{3}$. This result explains the non-formation of the $\left[\mathrm{Pu}(\mathrm{TPIP})_{4}\right]$.

Finally, the DFT results confirm that the smaller number of TIPIP- ligands in the Pu(IV) structures compared to TPIP- is due to steric effects while the TIPIP- ligand is a stronger donor ligand from an electronic point of view. Therefore, at the end, the TIPIP complex lean to the formation of complexes with lower metal:ligand stoichiometry than the $\mathrm{Pu}(\mathrm{IV})$-TPIP one with $1: 2$ and 1:3 respectively.

Concerning the $\mathrm{Pu}(\mathrm{VI})$ syntheses, in acidic aqueous phase, the ligands become protonated. The protonation ability of TIPIP- is more important than for the TPIP- ligand because of the phenyl electronwithdrawing inductive or mesomeric effects. Therefore, the TIPIP ligand is fully protonated in $\mathbf{4}$ whereas one TPIP out of the two is protonated in 3. With different ligand protonation states and denticities between $\mathbf{3}$ and $\mathbf{4}$ (bidentate for $\mathbf{4}$ and monodentate for $\mathbf{3}$ ), the comparison of the distances does not make sense. Nevertheless, as the TIPIP-Pu(IV) interaction is greater than for the TPIP ligand, the same is expected for $\mathrm{Pu}(\mathrm{VI})$. 
${ }^{1}$ D. Clark, S. Hecker, G. Jarvinen, M. Neu, Plutonium. In The Chemistry of the Actinide and Transactinide Elements, L. Morss, N. Edelstein, J. Fuger, Eds. Springer Netherlands: 2006; pp 813-1264.

${ }^{2}$ R.J. Baker, New Reactivity of the Uranyl(VI) Ion, Chem. Eur. J., 2012, 18, 16258-16271.

${ }^{3}$ I.A. Charushnikova, N.N. Krot, Z.A. Starikova, Crystal structure of a complex of Pu(VI) nitrate with triphenylphosphine oxide, [PuO2(NO3)2(OP(C6H5)3)2], Radiochemistry, 2007, 49(6), 561-564.

${ }^{4}$ I.A. Charushnikova, N.N. Krot, Z.A. Starikova, I.N. Polyakova, Crystal structure of complexes of Np(VI) and Pu(VI) perchlorates with triphenylphosphine oxide, $[\mathrm{NpO} 2(\mathrm{OP}(\mathrm{C} 6 \mathrm{H} 5) 3) 4](\mathrm{ClO} 4) 2$ and $[\mathrm{PuO} 2(\mathrm{OP}(\mathrm{C} 6 \mathrm{H} 5) 3) 4](\mathrm{ClO} 4) 2$, Radiochemistry 2007, 49(5), 464-469.

\section{Acknowledgements}

The authors would like to thank the FP7-Euratom TALISMAN project, for funding a joint research project under JRP n TALI_C05-04, the Leverhulme Trust for funding a Research Leadership Award (LSN) including postdoctoral funding (KG) grant number RL-2012-072, and the CEAMarcoule and The University of Manchester for support. 
${ }^{5}$ S-Y. Kim, K. Takao, Y. Haga, E. Yamamoto, Y. Kawata, Y. Morita, K. Nishimura, Y. Ikeda, Molecular and Crystal Structures of Plutonyl(VI) Nitrate Complexes with $N$-Alkylated 2-Pyrrolidone Derivatives: Cocrystallization Potentiality of $\mathrm{U}^{\mathrm{VI}}$ and Pu $\mathrm{Pu}^{\mathrm{VI}}$, Cryst. Growth Des., 2010, 10, 2033-2036.

${ }^{6}$ G. Tian, S. J. Teat, L. Rao, Formation, structure, and optical properties of $\mathrm{PuO}_{2}{ }^{2+}$ complexes with N,N,N',N'-tetramethyl-3-oxaglutaramide, Inorg. Chem. Commun., 2014, 44, 32-36.

${ }^{7}$ C. Xu, G. Tian, S. J. Teat, G. Liu, L. Rao, Thermodynamic and Structural Trends in Hexavalent Actinyl Cations: Complexation of Dipicolinic Acid with $\mathrm{NpO}_{2}{ }^{2+}$ and $\mathrm{PuO}_{2}{ }^{2+}$ in Comparison with $\mathrm{UO}_{2}{ }^{2+}$, Chem. Eur. J., 2013, 19, 16690-16698.

8 A. B. Yusov, M. S. Grigor'ev, A. M. Fedoseev, Interaction of $\mathrm{An}(\mathrm{VI})(\mathrm{An}=\mathrm{U}, \mathrm{Np}, \mathrm{Pu})$ and $\mathrm{Np}(\mathrm{V})$ with 2,3pyridinedicarboxylic (quinolinic) acid $\left(\mathrm{H}_{2} \mathrm{Quin}\right)$ : Complexation in aqueous solutions, synthesis and structure of the complexes $\left[\mathrm{UO}_{2}(\mathrm{HQuin})_{2}\right],\left[\left(\mathrm{NpO}_{2}\right)_{2}(\mathrm{HQuin})_{2}\left(\mathrm{C}_{6} \mathrm{H}_{4} \mathrm{NO}_{3}\right)_{2}\right] \cdot 2 \mathrm{H}_{2} \mathrm{O}$, and $\left[\mathrm{PuO}_{2} \mathrm{Quin}\left(\mathrm{H}_{2} \mathrm{O}\right)\right]$, Radiochemistry, 2013, 55, 16-25.

${ }^{9}$ A. B. Yusov, V. I. Mishkevich, A. M. Fedoseev, M. S. Grigor'ev, Complexation of An(VI) (An = U, Np, Pu, Am) with 2,6pyridinedicarboxylic acid in aqueous solutions. Synthesis and structures of new crystalline compounds of U(VI), Np(VI), and $\mathrm{Pu}(\mathrm{VI})$, Radiochemistry, 2013, 55, 269-278.

${ }^{10}$ N. Condamines, C. Musikas, The extraction by N,N-dialkylamides .II. Extraction of actinide cations, Solvent Extr. Ion Exch., 1992, 10, 69-100.

${ }^{11}$ P. N. Pathak, D. R. Prabhu, P. B. Ruikar, V. K. Mancha, Evaluation of di(2-ethylhexayl)isobutyramide (D2EHIBA) as a process extractant for the recovery of ${ }^{233} \mathrm{U}$ from irradiated Th, Solvent Extr. Ion Exch., 2002, 20, $293-311$.

12 T. H. Siddall, M. O. N. Fulda, G.S. Nichols, Nuclear Technology: Chemistry and Chemical Engineering, DP 541; 1961.

${ }^{13}$ M. Miguirditchian, P. Baron, S. Lopes Moreira, G. Milanole, C. Marie, Novel dissymmetric N,N-dialkylamides, the synthesis thereof and uses of same. WO2017017193A1, 2017.

${ }^{14}$ K. L. Nash, The Chemistry of TALSPEAK: A Review of the Science, Solvent Extr. Ion Exch., 2015, 33, 1-55.

${ }^{15}$ G. J. Lumetta, A. J. Casella, B. M. Rapko, T. G. Levitskaia, N. K. Pence, J. C. Carter, C. M. Niver, M. R. Smoot, An Advanced TALSPEAK Concept Using 2-Ethylhexylphosphonic Acid Mono-2-Ethylhexyl Ester as the Extractant, Solvent Extr. Ion Exch., 2015, 33, 211-223.

${ }^{16}$ A. P. Paiva, P. Malik, Recent advances on the chemistry of solvent extraction applied to the reprocessing of spent nuclear fuels and radioactive wastes, J. Radioanal. Nucl. Chem., 2004, 261, 485-496.

${ }^{17}$ E. P. Horwitz, W. W. Schulz, The TRUEX Process: A Vital Tool for the Disposal of U.S. Defense Waste; Elsevier: London, U.K., 1991.

18 D. Cupertino, D. J. Birdsall, A. M. Z. Slawin, J. D. Woollins, The preparation and coordination chemistry of ${ }^{{ }^{2}}{ }_{2} \mathrm{P}(\mathrm{E}) \mathrm{NHP}\left(\mathrm{E}^{\prime}\right) \mathrm{Pr}_{2}\left(\mathrm{E}, \mathrm{E}^{\prime}=\mathrm{Se} ; \mathrm{E}=\mathrm{Se}, \mathrm{E}^{\prime}=\mathrm{S} ; \mathrm{E}=\mathrm{S}, \mathrm{E}^{\prime}=\mathrm{O} ; \mathrm{E}, \mathrm{E}^{\prime}=\mathrm{O}\right)$, Inorg. Chim. Acta, 1999, $290,1-7$.

19 A. Carvalho, V. García-Montalvo, A. Domingos, R. Cea-Olivares, N. Marques, A. Pires de Matos, Synthesis and characterization of thorium and uranium tetraphenylimidophosphinate complexes. Crystal and molecular structures of Th(tpip) ${ }_{4}$, $\mathrm{U}(\text { tpip })_{4}$ and $\mathrm{UCl}(\text { tpip) })_{3}$, Polyhedron, 2000, 19, 1699-1705.

${ }^{20}$ M. P. Redmond, S. M. Cornet, S. D. Woodall, D. Whittaker, D. Collison, M. Helliwell, L. S. Natrajan, Probing the local coordination environment and nuclearity of uranyl(VI) complexes in non-aqueous media by emission spectroscopy, Dalton Trans., 2011, 40, 3914-3926.

${ }^{21}$ S. D. Woodall, A. N. Swinburne, N. Lal Banik, A. Kerridge, P. Di Pietro, C. Adam, P. Kaden, L.S. Natrajan, Neptunyl(VI) centred visible LMCT emission directly observable in the presence of uranyl(VI), Chem. Commun., 2015, 51, 5402-5405.

22 S. D. Woodall, Investigating the Coordination Chemistry and Oxidation State Stability of Actinyl and Actinide Ions and Consequent Effects on their Emission Profiles. Ph.D. Thesis, University of Manchester, 2014.

${ }^{23}$ S. Randall, Preparation and Investigation into the Optical Properties of Air Sensitive F-Block Complexes, Ph.D. Thesis, The University of Manchester, 2015.

${ }^{24}$ K. H. Williams, J. R. Bargar, J. R. Lloyd, D. R. Lovley, Bioremediation of uranium-contaminated groundwater: a systems approach to subsurface biogeochemistry, Curr. Opin. Biotechnol., 2013, 24, 489-497.

${ }^{25} \mathrm{H}$. Steele, R. J. Taylor, A theoretical study of the inner-sphere disproportionation reaction mechanism of the pentavalent actinyl ions, Inorg. Chem., 2007, 46, 6311-6318.

${ }^{26}$ M. J. Sarsfield, R. J. Taylor, C. J. Maher, Neptunium(V) disproportionation and cation-cation interactions in TBP/kerosene solvent, Radiochim. Acta, 2007, 95, 677-682.

${ }^{27}$ F. T. Wang, J. Najdzionek, K. L. Leneker, H. Wasserman, D. M. Braitsch, A Facile Synthesis of Imidotetraphenyldiphosphinic Acids, Synth. React. Inorg. Met., 1978, 8, 119-125.

28 S. D. Reilly, B. L. Scott, A. J. Gaunt, $\left[\mathrm{N}(n-\mathrm{Bu})_{4}\right]_{2}\left[\mathrm{Pu}\left(\mathrm{NO}_{3}\right)_{6}\right]$ and $\left[\mathrm{N}(n-\mathrm{Bu})_{4}\right]_{2}\left[\mathrm{PuCl}_{6}\right]$ : Starting Materials To Facilitate Nonaqueous Plutonium(IV) Chemistry, Inorg. Chem,. 2012, 51, 9165-9167.

${ }^{29}$ G. M. Sheldrick, SADABS, Empirical absorption correction program based upon the method of Blessing.

${ }^{30}$ L. Krause, R. Herbst-Irmer, G. M. Sheldrick, D. Stalke, Comparison of silver and molybdenum microfocus X-ray sources for single-crystal structure determination, J. Appl. Crystallogr., 2015, 48, 3-10.

${ }^{31}$ R. Blessing, An empirical correction for absorption anisotropy, Acta Cryst. Sect. A, 1995, 51, 33-38.

${ }^{32}$ G. Sheldrick, SHELXT - Integrated space-group and crystal-structure determination, Acta Cryst. Sect. C, 2015, 71, 3-8.

33 O. V. Dolomanov, L. J. Bourhis, R. J. Gildea, J. A. K. Howard, H. Puschmann, OLEX2: a complete structure solution, refinement and analysis program, J. Appl. Crystallogr., 2009, 42, 339-341.

${ }^{34}$ L. Berthon, N. Zorz, B. Gannaz, S. Lagrave, T. Retegan, A. Fermvik, C. Ekberg, IOP Conference Series: Material Science and Engineering, 2010, 9: 012059/012051-012059/012058. 
${ }^{35}$ I. Farnan, C. Berthon, SPR-Nuclear Magnetic Resonance, Vol 45, chap. 3, 2016, 96-141.

${ }^{36}$ X. Y. Cao, M. Dolg, H. Stoll, Valence basis sets for relativistic energy-consistent small-core actinide pseudopotentials, $J$. Chem. Phys., 2003, 118, 487-496.

${ }^{37}$ GAUSSIAN 09, M. J. Frisch, G. W. Trucks, H. B. Schlegel, G. E. Scuseria, M. A. Robb, et al, 2009.

38 A. Moritz, X. Y. Cao, M. Dolg, Quasirelativistic energy-consistent 5f-in-core pseudopotentials for trivalent actinide elements, Theor. Chem. Acc., 2007, 117, 473-481.

${ }^{39}$ A. Schafer, C. Huber and R. Ahlrichs, Fully optimized contracted Gaussian basis sets of triple zeta valence quality for atoms Li to Kr, J. Chem. Phys., 1994, 100, 5829-5835.

${ }^{40} \mathrm{R}$. Shannon, Revised effective ionic radii and systematic studies of interatomic distances in halides and chalcogenides, Acta Cryst. Sect.A, 1976, 32, 751-767.

${ }^{41}$ K. Aparna, S.S. Krishnamurthy, M. Nethaji, Synthetic, spectroscopic and structural studies on uranium and thorium complexes of diphosphazane dioxides, J. Chem. Soc. Dalton Trans., 1995, 2991-2997.

${ }^{42}$ Q-F Zhang, Z. Yu, A. Rothenberger, D. Fenske, W-H Leung, Rectangular tetranuclear silver(I) and $\mu$ 8-selenide-centered octanuclear copper(I) complexes containing bis(diphenylphosphino)amide ligands, Inorg. Chim. Acta, 2007, 360, 1568-1574.

${ }^{43}$ P.L. Anto, R.J. Anto, H.T. Varghese, C.Y. Panicker, D. Philip, Vibrational spectroscopic studies and $a b$ initio calculations of phenyl phosphate disodium salt, J. Raman Spectrosc., 2010, 41, 113-119.

44 O. Siiman, J. Vetuskey, Synthesis of copper thio- and dithioimidodiphosphinates. Infrared and Raman spectra of imidodiphosphinates, Inorg. Chem., 1980, 19, 1672-1680.

${ }^{45}$ R. Colton, A. Dagostino, J. C. Traeger, Electrospray mass spectrometry applied to inorganic and organometallic chemistry, Mass Spectrom. Rev., 1995, 14, 79-106.

${ }^{46}$ V.B. Di Marco, G.G Bombi, Electrospray mass spectrometry (ESI-MS) in the study of metal-ligand solution equilibria, Mass Spectrom. Rev., 2006, 25, 347-379.

${ }^{47}$ G. R. Agnes, G. Horlick, Electrospray Mass Spectrometry as a Technique for Elemental Analysis: Preliminary Results, Appl. Spectrosc., 1992, 46, 401-406.

${ }^{48}$ G. S. Groenewold, M. J. Van Stipdonk, G. L. Gresham, W. Chien, K. Bulleigh, A. Howard, Collision-induced dissociation tandem mass spectrometry of desferrioxamine siderophore complexes from electrospray ionization of $\mathrm{UO} 2(2+), \mathrm{Fe} 3+$ and $\mathrm{Ca} 2+$ solutions, J. Mass Spectrom., 2004, 39, 752-761.

49 C. Moulin, B. Amekraz, S. Hubert, V. Moulin, Study of thorium hydrolysis species by electrospray-ionization mass spectrometry, Anal. Chim. Acta, 2001, 441, 269-279.

${ }^{50}$ C. Walther, M. Fuss, S. Buechner, H. Geckeis, Stability of Th(IV) polymers measured by electrospray mass spectrometry and laser-induced breakdown detection, J. Radioanal. Nucl. Chem., 2009, 282, 1003-1008.

${ }^{51}$ C. Walther, M. Fuss, S. Buechner, Formation and hydrolysis of polynuclear Th(IV) complexes - a nano-electrospray massspectrometry study, Radiochim. Acta, 2008, 96, 411-425.

52 M. J. Keith-Roach, M. V. Buratti, P. J. Worsfold, Thorium Complexation by Hydroxamate Siderophores in Perturbed Multicomponent Systems Using Flow Injection Electrospray Ionization Mass Spectrometry, Anal. Chem., 2005, 77, 7335-7341.

${ }^{53}$ A. J. Cartwright, C. C. May, P. J. Worsfold, M. J. Keith-Roach, Characterisation of thorium-ethylenediaminetetraacetic acid and thorium-nitrilotriacetic acid species by electrospray ionisation-mass spectrometry, Anal. Chim. Acta, 2007, 590, 125-131.

${ }^{54}$ E. Reinoso-Maset, P. J. Worsfold, M. J. Keith-Roach, Evaluation of electrospray ionisation mass spectrometry as a technique for the investigation of competitive interactions: A case study of the ternary Th-Mn-EDTA system, Rapid Commun. Mass Spectrom., 2012, 26, 2755-2762.

${ }_{55}^{5}$ Y. Gong, H-S. Hu, G. Tian, L. Rao, J. Li, J. K. Gibson, A Tetrapositive Metal Ion in the Gas Phase: Thorium(IV) Coordinated by Neutral Tridentate Ligands, Angew. Chem. Int. Ed., 2013, 52, 6885-6888.

${ }^{56}$ C.L. Xiao, C.Z. Wang, L. Mei, X.R. Zhang, N. Wall, Y.L. Zhao, Z.F. Chai, W.Q. Shi, Europium, uranyl, and thoriumphenanthroline amide complexes in acetonitrile solution: an ESI-MS and DFT combined investigation, Dalton Trans., 2015, 44, $14376-14387$.

${ }^{57}$ M.S. Espinosa, R. Servant, P.A. Babay, ESI-MS speciation analysis of neodymium and thorium complexed with nitrilotriacetic and picolinic acids, Microchem. J., 2018, 142, 352-358.

${ }^{58}$ T. Retegan, L. Berthon, C. Ekberg, A. Fermvik, G. Skarnemark, N. Zorz, Electrospray Ionization Mass Spectrometry Investigation of BTBP - Lanthanide(III) and Actinide(III) Complexes, Solvent Extr. Ion Exc., 2009, 27, 663-682.

${ }^{59}$ Y. Gong, G. X. Tian, L. F. Rao, J. K. Gibson, Dissociation of Diglycolamide Complexes of $\mathrm{Ln}^{3+}(\mathrm{Ln}=\mathrm{La}-\mathrm{Lu})$ and $\mathrm{An}^{3+}(\mathrm{An}=$ $\mathrm{Pu}, \mathrm{Am}, \mathrm{Cm}$ ): Redox Chemistry of $4 \mathrm{f}$ and $5 \mathrm{f}$ Elements in the Gas Phase Parallels Solution Behavior, Inorg. Chem., 2014, 53, 12135-12140.

${ }^{60}$ M. Audras, L. Berthon, N. Martin, N. Zorz, P. Moisy, Investigation of actinides(III)-DOTA complexes by electrospray ionization mass spectrometry, J. Radioanal. Nucl. Chem., 2015, 303, 1897-1909.

${ }^{61}$ A. F. Lucena, C. Lourenco, M. C. Michelini, P. X. Rutkowski, J. M. Carretas, N. Zorz, L. Berthon, A. Dias, M. Conceicao Oliveira, J. K. Gibson, J. Marcalo, Synthesis and hydrolysis of gas-phase lanthanide and actinide oxide nitrate complexes: a correspondence to trivalent metal ion redox potentials and ionization energies, Phys. Chem. Chem. Phys., 2015, 15, 9942-9950.

${ }^{62}$ S. Mostapha, F. Fontaine-Vive, L. Berthon, N. Boubals, N. Zorz, P.L. Solari, M-C. Charbonnel, C. Den Auwer, On the structure of thorium and americium adenosine triphosphate complexes, Int. J. Radiat. Biol., 2014, 90, 966-974.

${ }_{63}$ S.K Aggarwal, A review on the mass spectrometric studies of americium: Present status and future perspective, Mass Spectrom. Rev., 2018, 37, 43-56. 
${ }^{64}$ A. J. Francis, C. J. Dodge, J. B. Gillow, Biotransformation of plutonium complexed with citric acid, Radiochim. Acta, 2006, 94, 731-737.

${ }^{65}$ D. Rios, M. C. Michelini, A. F. Lucena, J. Marcalo, T. H. Bray, J. K. Gibson, Gas-Phase Uranyl, Neptunyl, and Plutonyl: Hydration and Oxidation Studied by Experiment and Theory, Inorg. Chem., 2012, 51, 6603-6614.

${ }^{66}$ D. Rios, P. X. Rutkowski, D. K. Shuh, T. H. Bray, J. K. Gibson, M. J. Van Stipdonk, Electron transfer dissociation of dipositive uranyl and plutonyl coordination complexes, J. Mass Spectrom., 2011, 46, 1247-1254.

${ }^{67}$ D. Rios, P. X. Rutkowski, M. J. Van Stipdonk, J. K. Gibson, Gas-Phase Coordination Complexes of Dipositive Plutonyl, $\mathrm{PuO}_{2}{ }^{2+}$ : Chemical Diversity Across the Actinyl Series, Inorg. Chem., 2011, 50, 4781-4790.

${ }^{68}$ R. Maurice, E. Renault, Y. Gong, P. X. Rutkowski, J. K. Gibson, Synthesis and Structures of Plutonyl Nitrate Complexes: Is Plutonium Heptavalent in $\mathrm{PuO}_{3}\left(\mathrm{NO}_{3}\right)_{2}^{-}$?, Inorg. Chem., 2015, 54, 2367-2373.

${ }^{69} \mathrm{M}$. Steppert, C. Walther, Mass spectrometric characterization and quantification of $\mathrm{Pu}(\mathrm{VI})$ hydrolysis products, Radiochim. Acta, 2013, 101, 307-311.

70 Phuong D. Dau, Rémi Maurice, Eric Renault, and John K. Gibson, Heptavalent Neptunium in a Gas-Phase Complex: $\left(\mathrm{Np}^{\mathrm{VII}} \mathrm{O}_{3}{ }^{+}\right)\left(\mathrm{NO}_{3}{ }^{-}\right)_{2}$, Inorg. Chem., 2016, 55, 9830-9837.

71 M. Steppert, C. Walther, M. Fuss, S. Buechner, On the polymerization of hexavalent uranium. An electrospray mass spectrometry study, Rapid Commun. Mass Spectrom., 2012, 26, 583-591.

${ }^{72}$ M. Van Stipdonk, V. Anbalagan, W. Chien, G. Gresham, G. Groenewold, D. Hanna, Elucidation of the collision induced dissociation pathways of water and alcohol coordinated complexes containing the uranyl cation, J. Am. Soc. Mass Spectrom., 2003, 14, 1205-1214.

${ }^{73}$ G.L. Gresham, A. Dinescu, M.T. Benson, M.J. Van Stipdonk, G.S. Groenewold, Investigation of Uranyl Nitrate Ion Pairs Complexed with Amide Ligands Using Electrospray Ionization Ion Trap Mass Spectrometry and Density Functional Theory, $J$. Phys. Chem. A, 2011, 115, 3497-3508.

74 P.X. Rutkowski, D. Rios, J.K. Gibson, M.J. Van Stipdonk, Gas-Phase Coordination Complexes of UVIO $\{2 / 2+\}$, NpVIO $\{2 / 2+\}$, and PuVIO $\{2 / 2+\}$ with Dimethylformamide J. Am. Soc. Mass Spectrom., 2011, 22, 2042-2048.

75 Y. Gong, H.S. Hu, L.F. Rao, J. Li, J.K. Gibson, Experimental and Theoretical Studies on the Fragmentation of Gas-Phase Uranyl-, Neptunyl-, and Plutonyl-Diglycolamide Complexes, J. Phys. Chem. A, 2013, 117, 10544-10550.

${ }^{76}$ A.F. Lucena, J.M. Carretas, J. Marcalo, M.C. Michelini, Y. Gong, J.K Gibson, Gas-Phase Reactions of Molecular Oxygen with Uranyl(V) Anionic Complexes-Synthesis and Characterization of New Superoxides of Uranyl(VI), J. Phys. Chem. A, 2015, 119, 3628-3635.

77 A.F. Lucena, J.M. Carretas, J. Marcalo, M.D. Michelini, P.X. Rutkowski, J.K. Gibson, Dissociation of Gas-Phase Bimetallic Clusters as a Probe of Charge Densities: The Effective Charge of Uranyl, J. Phys. Chem. A, 2014, 118, 2159-2166.

78 J. Drader, N. P. Martin, N. Boubals, N. Zorz, P. Guilbaud, L. Berthon, Redox behavior of gas phase Pu(IV)-monodentate ligand complexes: an investigation by electrospray ionization mass spectrometry, J. Radioanal. Nucl. Chem., 2016, 310, 441-451.

79 A. P. Hunter, A. M. J. Lees, A. W. G.Platt, Synthesis, structures and mass spectrometry of lanthanide nitrate complexes with tricyclohexylphosphine oxide, Polyhedron, 2007, 26, 4865-4876.

${ }^{80}$ M.C. Crowe, R.N. Kapoor, F. Cervantes-Lee, L. Parkanyi, L. Schulte, K.H. Pannell, J.S. Brodbelt, Investigating Bidentate and Tridentate Carbamoylmethylphosphine Oxide Ligand Interactions with Rare-Earth Elements Using Electrospray Ionization Quadrupole Ion Trap Mass Spectrometry, Inorg. Chem., 2005, 44, 6415-6424.

${ }^{81}$ NMR of Paramagnetic Molecules. In NMR of Paramagnetic Molecules, W. D. Horrocks, R. H. Holm, Eds. Academic Press: 1973.

${ }^{82}$ L.J. L. Häller, N. Kaltsoyannis, M. J. Sarsfield, I. May, S. M. Cornet, and M. P. Redmond, M. Helliwell, A Structural and Theoretical Investigation of Equatorial cis and trans Uranyl Phosphinimine and Uranyl Phosphine Oxide Complexes $\mathrm{UO}_{2} \mathrm{Cl}_{2}\left(\mathrm{Cy}_{3} \mathrm{PNH}\right)_{2}$ and $\mathrm{UO}_{2} \mathrm{Cl}_{2}\left(\mathrm{Cy}_{3} \mathrm{PO}\right)_{2}$, Inorg. Chem., 2007, 46, 4868-4875.

${ }^{83}$ S. M. Cornet, I. May, M. J. Sarsfield, N. Kaltsoyannis, J. Haller, C. Den Auwer, D. Meyer, Actinyl chemistry across the U, Np and $\mathrm{Pu}$ series, $J$ Alloy Compd, 2007, 444-445, 453-456.

${ }_{84}$ M. S. Grigoriev, M.Yu. Antipin, N. N. Krot, A. A. Bessonov, Crystal structures of Np(VI) and Pu(VI) phthalates, $\left[\mathrm{NpO}_{2}\left\{(\mathrm{OOC})_{2} \mathrm{C}_{6} \mathrm{H}_{4}\right\} \mathrm{H}_{2} \mathrm{O}\right] \cdot 1 / 3 \mathrm{H}_{2} \mathrm{O}$ and $\left[\mathrm{PuO}_{2}\left\{(\mathrm{OOC})_{2} \mathrm{C}_{6} \mathrm{H}_{4}\right\} \mathrm{H}_{2} \mathrm{O}\right] \cdot \mathrm{H}_{2} \mathrm{O}$, Radiochim. Acta, 2004, 92, 405-409.

${ }^{85}$ M. Rietzel, H. W. Roesky, K. V. Katti, H. G. Schmidt, R. Herbst-Irmer, M. Noltemeyer, G. M. Sheldrick, M. C. R. Symons, A. Abu-Raqabah, Unexpected nitrogen-oxygen exchange reactions in cyclic metallaphosphazenes; synthesis and $X$-ray crystal structures of $\left[\mathrm{Mo}\left(\mathrm{OPPh}_{2} \mathrm{NHPPh}_{2} \mathrm{O}\right) \mathrm{O}_{2} \mathrm{Cl}_{2}\right]$, $\left[\mathrm{Mo}\left(\mathrm{OPPh}_{2} \mathrm{NPPh}_{2} \mathrm{O}\right)_{2}(\mathrm{O}) \mathrm{Cl}\right]$, and $\left[\mathrm{Mo}\left(\mathrm{OPPh}_{2} \mathrm{NPPh}_{2} \mathrm{O}\right)_{2} \mathrm{O}_{2}\right]$, J. Chem. Soc., Dalton Trans., 1990, 2387-2392.

${ }^{86}$ H. Liu, M. Jose Calhorda, M. G. B. Drew, V. Felix, J. Novosad, L. F. Veiros, F. Fabrizi de Biani, P. Zanello, New Cu(I) and Ag(I) binuclear complexes containing the dppa ligand, J. Chem. Soc., Dalton Trans., 2002, 4365-4374.

${ }^{87}$ N. Levesanos, A. Grigoropoulos, C. P. Raptopoulou, V. Psycharis, P. Kyritsis, Coordination of ${ }^{i} \operatorname{Pr}_{2} \mathrm{P}(\mathrm{O}) \mathrm{NHP}(\mathrm{O})^{\mathrm{i}} \mathrm{Pr}_{2}$ to $\mathrm{Co}{ }^{(\mathrm{II})}$ : Simultaneous formation of octahedral and tetrahedral complexes, Inorg. Chem. Commun., 2013, 30, 34-38.

${ }^{88}$ D. Cohen, The absorption spectra of plutonium ions in perchloric acid solutions, J. Inorg. Nucl. Chem., 1961, 18, $211-218$. 
1

2

3

4

5

6

7

8

9

10

11

12

14

15

16

17

18

19

20

21

22

23

24

25

26

27

28

29

30

31

32

33

34

35

36

38

39

40

41

42

43

44

45

46

47

48

49

50

57

58

59

60

ACS Paragon Plus Environment 


\section{TOC "for table and contents only"}

The coordination chemistry of plutonium(IV) and plutonium(VI) with the complexing agents tetraphenyl and tetra-isopropyl imidodiphosphinate (TPIP- and TIPIP-) is reported. The resultant complexes have been characterized using a combination of X-ray structural studies, NMR, optical, and vibrational spectroscopies and electrospray ionization mass spectrometry. The influence of the R-group $(\mathrm{R}=\mathrm{phenyl}$ or ${ }^{i} \mathrm{Pr}$ ) on the nature of the complex is discussed with the help of DFT studies.

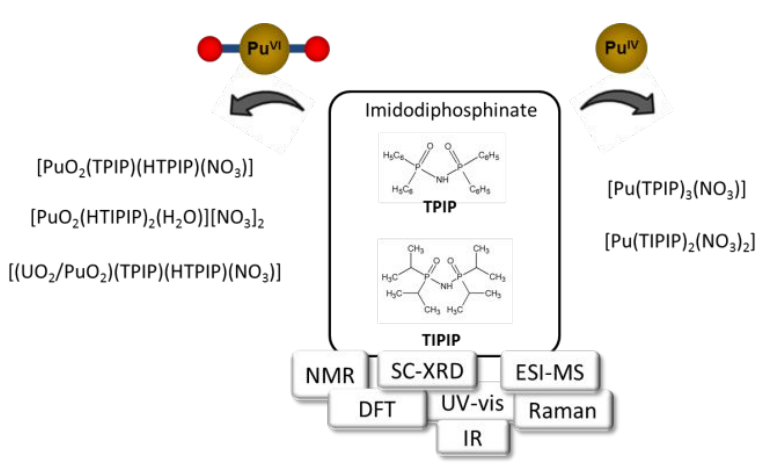

